Multi-keV X-Ray Source Development Experiments on the National Ignition Facility

K. B. Fournier, M. J. May, J. D. Colvin, J. O. Kane, M. Schneider, E. Dewald, C. A. Thomas, S. Compton, R. E. Marrs, J. Moody, E. Bond, P. Michel, J. H. Fisher, C. D. Newlander, J. F. Davis

May 11,2010

Physics of Plasmas 
This document was prepared as an account of work sponsored by an agency of the United States government. Neither the United States government nor Lawrence Livermore National Security, LLC, nor any of their employees makes any warranty, expressed or implied, or assumes any legal liability or responsibility for the accuracy, completeness, or usefulness of any information, apparatus, product, or process disclosed, or represents that its use would not infringe privately owned rights. Reference herein to any specific commercial product, process, or service by trade name, trademark, manufacturer, or otherwise does not necessarily constitute or imply its endorsement, recommendation, or favoring by the United States government or Lawrence Livermore National Security, LLC. The views and opinions of authors expressed herein do not necessarily state or reflect those of the United States government or Lawrence Livermore National Security, LLC, and shall not be used for advertising or product endorsement purposes. 


\section{Multi-keV X-Ray Source Development Experiments on the National Ignition Facility}

K. B. Fournier, ${ }^{1, a)}$ M. J. May, ${ }^{1, \text { b) }}$ J. D. Colvin, ${ }^{1, c)}$ J. O. Kane ${ }^{1}$ M. Schneider, ${ }^{1}$ E. Dewald, ${ }^{1}$ C. A. Thomas, ${ }^{1}$

S. Compton, ${ }^{1}$ R. E. Marrs, ${ }^{1}$ J. Moody, ${ }^{1}$ E. Bond, ${ }^{1}$ P. Michel, ${ }^{1}$ J. H. Fisher, $\left.{ }^{2,}{ }^{d}\right)$ C. D. Newlander, ${ }^{2,}$ e) and J. F. Davis ${ }^{3, f)}$

1) Lawrence Livermore National Laboratory, Livermore, California 94551, USA

${ }^{2)}$ Gray Research, Inc., 655 Discovery Drive, Suite 300, Huntsville, AL 35806

3) Defense Threat Reduction Agency, 8725 John J. Kingman Rd., Fort Belvoir, VA 22060-6201

(Dated: 11 May 2010)

We report results from a five shot campaign carried out with Ar-Xe gas-filled targets at the National Ignition Facility (NIF). The targets were shot with $\approx 350 \mathrm{~kJ}$ of $3 \omega$ laser energy delivered with a 5 ns trapezoidal laser pulse. We report measured x-ray output from the target in different spectral bands both below and above $1.5 \mathrm{keV}$ photon energies: we find yields of $\approx 20.5 \mathrm{~kJ} / \mathrm{sr}$ with peak x-ray power approaching $4 \mathrm{TW} / \mathrm{sr}$ over all energies, as measured for the unique viewing angle of our detector, and $\approx 3.6 \mathrm{~kJ} / \mathrm{sr}$ with peak x-ray power of $1 \mathrm{TW} / \mathrm{sr}$ for $\mathrm{x}$ rays with energies $>3 \mathrm{keV}$. This is a laser-to-x-ray conversion efficiency of $13 \pm 1.3 \%$ for isotropic $\mathrm{x}$ rays with energies $>3 \mathrm{keV}$. Laser energy reflected by the target plasma for both inner and outer-cone beams is measured and found to be small, between 1-4\% of the drive energy. The energy emitted in hard $\mathrm{x}$ rays (with energies $>25 \mathrm{keV}$ ) is measured and found to be $\approx 1 \mathrm{~J} / \mathrm{sr}$. Two-dimensional imaging of the target plasma during the laser pulse confirms a fast, volumetric heating of the entire target, resulting in efficient laser-to-x-ray conversion. Post-shot simulations with a two-dimensional radiation-hydrodynamics code reproduce well the observed x-ray flux and fluence, backscattered light, and bulk target motion.

\section{INTRODUCTION}

Bright, multi-keV x-ray sources are needed for imaging and radiography applications ${ }^{1-4}$. Large, homogeneous sources are useful for area backlighters, and very bright sources can be apertured for point-projection backlighters ${ }^{5-7}$. High x-ray fluence sources across a range of x-ray energies are needed for studies of x-ray interaction with materials ${ }^{8-11}$. Maximizing the laser-to-x-ray conversion efficiency (CE) and tuning the spectral content of the x-ray source are crucial to satisfying the requirements of any backlighter or material-interaction application.

During the last decade, many research groups have been developing bright, multi-keV x-ray sources ${ }^{12-24}$. The goal has been to create millimeter-scale, homogeneous, keV-scale-temperature plasmas that are efficient laser-to-x-ray converters. Much of the work has focused on producing underdense plasmas, defined as plasmas with electron density below $0.25 n_{c r}$, where $n_{c r}$ is the critical density for laser light of wavelength $\lambda, n_{c r}=$ $1.1 \times 10^{21} / \lambda^{2}$ for $\lambda$ in microns. When the x-ray-emitting plasma is underdense, the laser can propagate (nearly)

\footnotetext{
a) fournier $2 @ 1 l n l . g o v$

b) may13@llnl.gov

c) colvin5@llnl.gov

d) jisher@gray-research.com

e) cdavidnewlander@yahoo.com

f) Also at Alme \& Associates, 1703 Belle View Blvd., Alexandria, Virginia 22307; John.Davis_Contractor@dtra.mil
}

supersonically through the target ${ }^{25}$ and efficiently ionize the target material thus efficiently producing x-ray emission. In Back et al. ${ }^{14}$, a prediction was made that for large laser powers (> $60 \mathrm{TW})$, laser-driven multi-keV xray sources achieve a new regime of double-digit laser-to$\mathrm{x}$-ray conversion efficiencies for photon energies greater than $\approx 5 \mathrm{keV}$ (see Fig. 4 in Ref. ${ }^{14}$ ). The calculations that support this prediction of enhanced CE relied on large target volumes that contain sufficient numbers of emitting ions.

In the intervening years, calculations have shown that the multi-keV emissivity of highly charged mid- and high$\mathrm{Z}$ ions in these plasmas is a strong function of temperature, with a different optimum temperature in different spectral bands ${ }^{26}$. As a result of the limited energy available at most laser research facilities, the plasma temperatures achievable have not necessarily been matched to the peak multi-keV x-ray emissivity. In this paper, we present the first demonstration of the National Ignition Facility's ${ }^{27,28}$ ability to generate multi-keV x-ray fluxes; these results are the largest ever multi-keV x-ray yields from laser-heated targets, which confirms reaching a new regime of high CE's for multi-keV x-ray sources.

\section{EXPERIMENTAL SET-UP}

The National Ignition Facility (NIF) is a 192-beam laser system ${ }^{28}$ now operating at the Lawrence Livermore National Laboratory. The facility was dedicated on May 29th, 2009. The facility is capable of delivering up to $1.8 \mathrm{MJ}$ of ultraviolet $(351 \mathrm{~nm}$ ) laser energy to mm-scale targets at the center of a $10 \mathrm{~m}$ diameter target chamber. 
In October and November 2009, a series of five shots were fired that characterized NIF's capability for producing ultra-low-debris, high-flux and high-fluence cold (energies $<10 \mathrm{keV}$ ) x-ray environments. The targets were driven with up to $75 \mathrm{TW}$ of laser power $(350 \mathrm{~kJ}$ of $3 \omega$ laser energy delivered in a 5 ns modified-flat-top pulse).

\section{A. Target Description}

The target design for the current experiments builds on experience at the Nova ${ }^{29}$ and Omega ${ }^{30}$ laser facilities using modeling and simulation tools that have been validated against experiments ${ }^{12-24}$. The desired x-ray source characteristics for the present experiments were: a) significant multi-keV x-ray output with energies $>3 \mathrm{keV}, \mathrm{b}$ ) $\mathrm{x}$-ray pulse width of order $5 \mathrm{~ns}$, and c) x-ray rise-time of order $1 \mathrm{~ns}$ or longer. The final target design was a result of a series of scoping calculations extrapolated from previous designs ${ }^{31}$ to NIF scale in target volume, laser pointing and focusing, assuming an input laser power of order $70 \mathrm{TW}$.

The targets for these experiments were thin-walled $(25 \mu \mathrm{m}), 4 \mathrm{~mm}$ long, $4 \mathrm{~mm}$ inner-diameter epoxy $\left(\mathrm{C}_{40} \mathrm{H}_{51} \mathrm{~N}_{2} \mathrm{O}_{7}, \rho=1.185 \mathrm{~g} / \mathrm{cm}^{3}\right)$ pipes designed to transmit $\mathrm{x}$ rays in the $1-10 \mathrm{keV}$ spectral band. Both sideon and end-on views of the gas-pipe target, including the mounting stalk and the fill lines, are shown in the photographs in Fig. 1. Also shown are the thin $(3500 \AA)$ polyimide windows across the laser entrance holes (LEHs). The windows were attached to $6.1 \mathrm{~mm}$ outer diameter washers that are visible in Fig. 1; when the gas pipe and washers are assembled, the total length of the assembly is $4.4 \mathrm{~mm}$. The pipes were filled with 1.2 atm of an Ar:Xe (65:35) mixture, which was chosen to produce (i) multi-keV $\mathrm{x}$ rays with energies $>3 \mathrm{keV}$, and (ii) to create a plasma with an electron density $\approx 0.1 n_{c r}$, assuming an ionization state of $\mathrm{Xe}^{44+}$ and $\mathrm{Ar}^{17+}$ during the shot. (These ion charge states are predicted in our pre-shot point-design simulations.) The atom density in the target plasma is computed as $n_{Z}=\left(N_{Z} / V\right)=\frac{f_{Z} P}{R T}$, where $n_{Z}$ is the number density of element $Z(Z=54$ for Xe and 18 for $\mathrm{Ar}$ ), $N_{Z}$ is the number of atoms of element $Z, f_{Z}$ is the fraction of atoms of element $Z$ in the target gas fill, $V$ is the target volume, $P$ is the target pressure, $R$ is the ideal gas constant, and $T$ is the pre-shot temperature of the target gas in Kelvin. The electron density is then found by $n_{e}=\Sigma_{Z}<q>n_{Z}$, where $\langle q>$ represents the average ion charge on an atom of element $Z$, and the sum is over all elements present. The gas-pipe targets had fill pressures that were measured to be within $1 \%$ of the requested pressure at shot time.

\section{B. Laser Energy and Power}

For all irradiation configurations used in the present experiments, we used $\approx 350 \mathrm{~kJ}$ of $3 \omega$ energy to drive our targets, see Fig. 2. It can be seen that the delivered energy consistently matched the requested energy. The shot-to-shot variation was better than $2 \%$, except for the case where we had to drop one bundle of eight beams right before shot N091104.

For these experiments, we created a custom pulse shape for the $3 \omega$ power at target chamber center (TCC). As was indicated by the pre-shot design simulations ${ }^{31}$, the emitted x-ray power closely tracks the laser power (see Sec. III A). Therefore, to have a nanosecond rise time in the x-ray power emitted from the target, we relaxed the natural rising edge of the NIF laser power to $1 \mathrm{~ns}$ from $\approx 150 \mathrm{ps}$. In addition, to have the $\mathrm{x}$-ray output from the target for $\mathrm{x}$ rays with energies $>3 \mathrm{keV}$ to have at least a $3 \mathrm{~ns}$ full width at half maximum (FWHM) or a total 6 ns shine time, we requested a laser pulse shape with a relaxed, linear rise in the laser power over $1 \mathrm{~ns}$, and a 4 ns flat top with nearly constant laser power of $\approx 74 \mathrm{TW}$. This requirement for a relaxed ramp in the laser power results in less efficient operation of the NIF frequency conversion crystals (KDP, or potassium dihydrogen phosphate) that take the $1 \omega$ fundamental light to the $3 \omega$ final wavelength. Thus, this pulse shape resulted in increased $1 \omega$ energy, which put our experiments near the facility's limits on energy to avoid initiation of damage sites in the laser optics. Figure 3 shows our requested laser power and the delivered laser power for the four shots in this campaign that delivered the full requested energy.

\section{Laser Pointing and Beam Smoothing}

The NIF laser beams enter the chamber in four cones that have azimuthal symmetry around the vertical axis of the target chamber (which is also the target's axis, see Sec. II A). The beam cones propagate to TCC with angles of $23.5^{\circ}, 30^{\circ}, 44.5^{\circ}$, and $50^{\circ}$. Half the beams in each cone come from the top of the NIF target chamber, while the other half come from the bottom. The $23.5^{\circ}$ and $30^{\circ}$ beams collectively are referred to as "inner cone" and the $44.5^{\circ}$ and $50^{\circ}$ beams are collectively referred to as "outer cone". We had two laser-irradiation configurations of our targets in the present experiments, one which used 132 beams, the other used 112 beams.

\section{1. $128+4$ beam configuration}

In the first configuration, we used a total of 132 beams, with all 128 outer cone beams (64 at $44.5^{\circ}$, split evenly from the top and bottom of the chamber, 64 at $50^{\circ}$, split evenly from top and bottom), and four $30^{\circ}$ beams. This 128+4-beam configuration was used for one shot (N091012-003-999). We overlapped the outer cone beams at the LEHs of the target creating an overlap intensity for 64 outer-cone beams at each LEH of $\approx 3.2 \times 10^{15} \mathrm{~W} / \mathrm{cm}^{2}$. Shown in Fig. 4a is a model of the laser intensity on the 


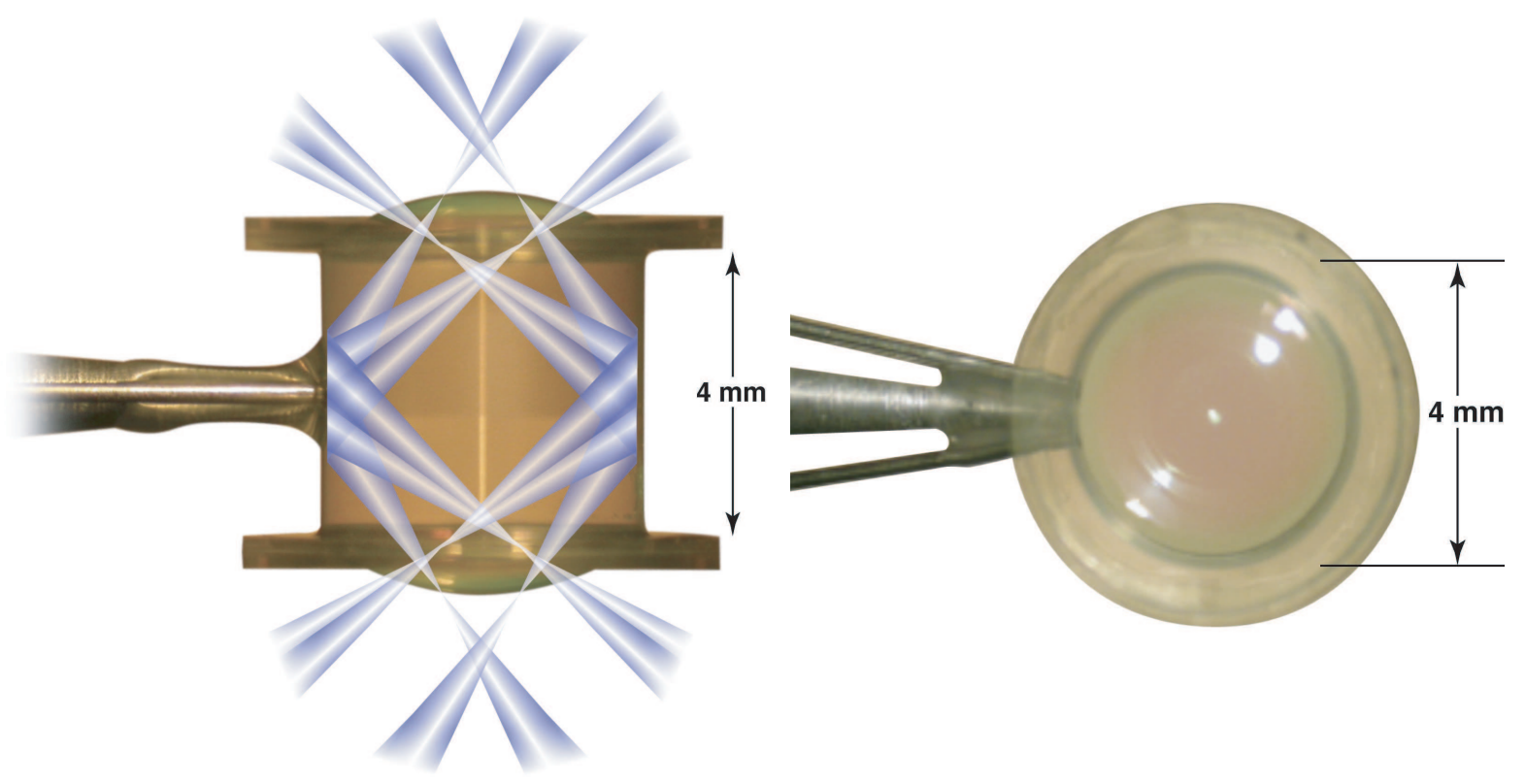

FIG. 1. (color online) Side-on (left) and face-on (right) views of the thin-walled gas pipes used as x-ray source targets in the present experiments. Cartoon laser beams are drawn in the side-on view showing how the $30^{\circ}, 44.5^{\circ}$ and $50^{\circ}$-cones were pointed with respect to the target's axis and laser-entrance holes.

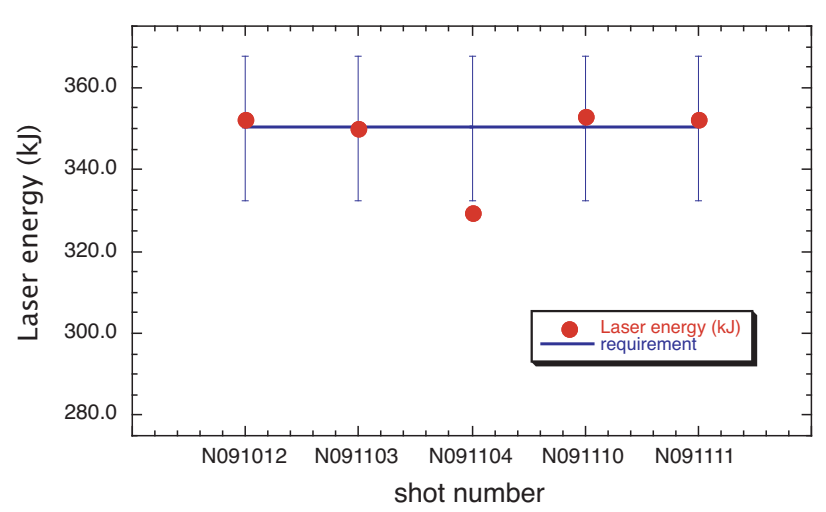

FIG. 2. (color online) The required (blue line) and delivered (red circles) $3 \omega$ laser energy for each of the five shots in our campaign. The error bars on the required energy represent a $\pm 5 \%$ deviation from the requested laser energy that was what we considered the maximum tolerable deviation. Only one shot, N091104, was outside the $\pm 5 \%$ range due to the need to drop one bundle (eight beams) just prior to the shot.

target's mid-plane from the full compliment of 128-outercone-beams pointed to the LEH. (The intensity that results from the model is an overestimate since it does not account for energy absorbed from the beams in the target gas.) In this configuration, the illumination produces

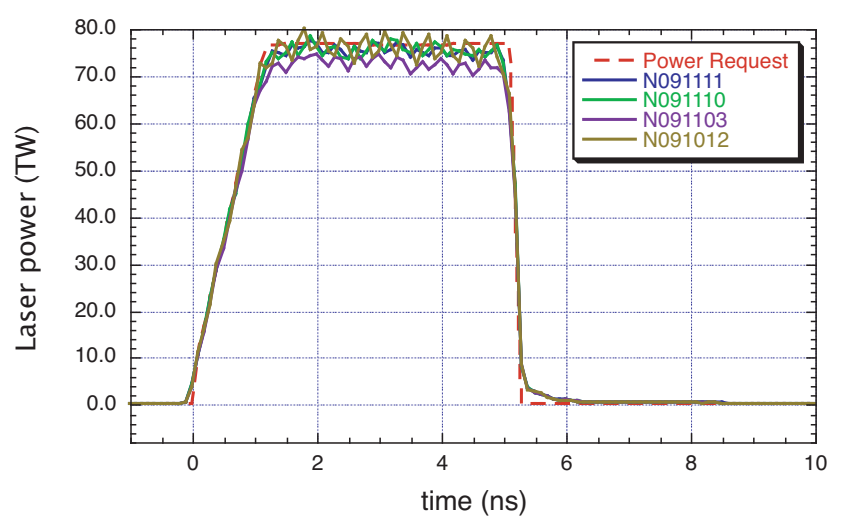

FIG. 3. (color online) The requested (red, dashed) and delivered (solid) $3 \omega$ laser power to the x-ray source targets at TCC for four of the full-power shots in this campaign.

a uniform band around the target's mid-plane. For the $128+4$-beam configuration, we also ran four $30^{\circ}$ beams in order to measure backscattered light from these innercone beams. These four beams (Quad 31B) were pointed to a position on the target's axis $1.3 \mathrm{~mm}$ outside the LEH. 
Direct Laser Power Deposited (TW/cm2)

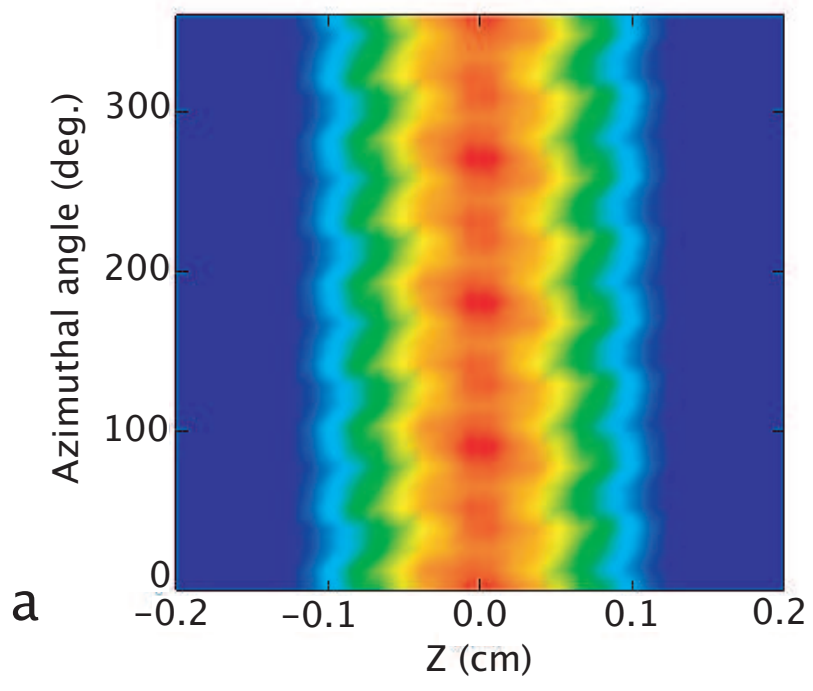

Direct Laser Power Deposited (TW/cm2)
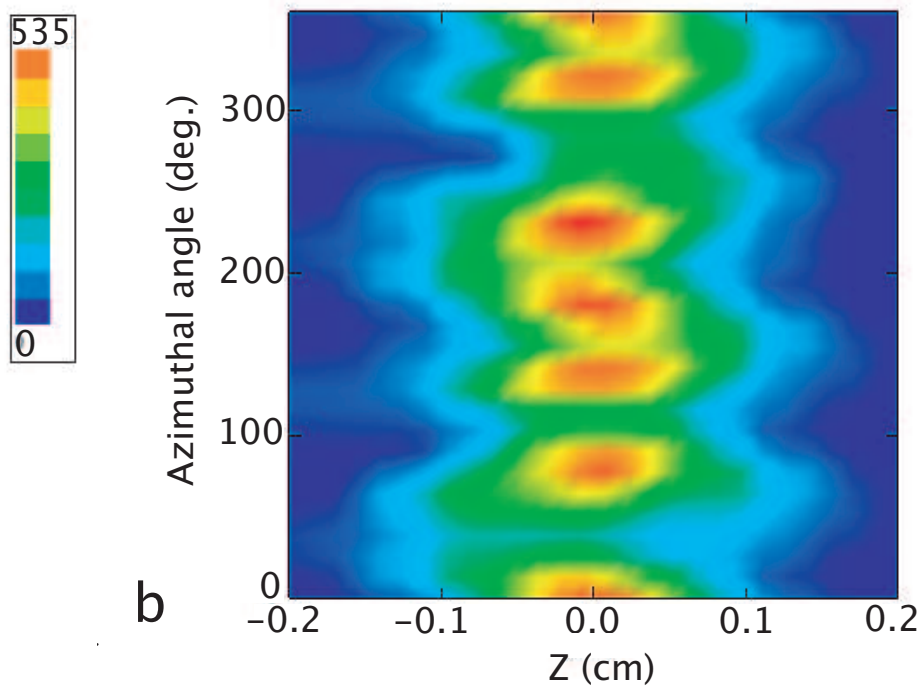

FIG. 4. (color online) (a) azimuthal map of the 128 outer-cone beams' laser intensity on the target's mid-plane in the 128+4beam-configuration, and (b) azimuthal map of the 112-beam-configuration laser intensity on the target's mid-plane. In the maps, the axial coordinate of the gas-pipe target runs (from $-2 \mathrm{~mm}$ to $+2 \mathrm{~mm}$ ) along the bottom of each image, and the azimuthal coordinate, from 0 to 360 degrees, runs up the side of each image.

\section{112 beam configuration}

The second configuration used a total of 112 beams, all 32 of the $30^{\circ}$ beams, split evenly from the top and bottom of the chamber, and 80 beams from both sets of outer-cone beams (predominantly the $50^{\circ}$ cone), with 40 each from the top and bottom of the chamber. This configuration was used for the remaining four shots in this campaign, although in one shot (N091104-002-999) the eight outer-cone beams of bundle 36 were dropped. In the case of the 112 beam configuration, the outer-cone beams were pointed to a position on the target's axis that was $0.5 \mathrm{~mm}$ inside the LEH, while the inner cone beams were pointed on the target's axis $1.3 \mathrm{~mm}$ outside the LEHs (see cartoon beams in Fig. 1). This results in an overlap intensity at the LEH of $\gtrsim 2.5 \times 10^{15} \mathrm{~W} / \mathrm{cm}^{2}$. Shown in Fig. 4b is a map of the laser intensity on the target's midplane for the 112-beam configuration. In the 112-beam configuration, there are two clusters of intensity, with a small asymmetry between them. The different symmetries in laser drive for the 128+4- and 112-beam configurations manifest themselves in two-dimensional images of the targets during the experiments (see Section III D).

\section{Beam smoothing techniques}

In order to minimize the variation in intensity across the focal spot of each beam, three beam-smoothing techniques were employed for these shots. Continuous

\begin{tabular}{lcc}
\hline \hline CPP name & $\begin{array}{c}\text { Beam cone angle } \\
\text { (deg.) }\end{array}$ & $\begin{array}{c}\text { Spot size } \\
(\mathrm{mm} \times \mathrm{mm})\end{array}$ \\
\hline Rev_1_inner & 30 & $0.824 \times 0.590$ \\
Rev_3 & 44.5 & $0.635 \times 0.367$ \\
Rev_1_outer & 50 & $0.593 \times 0.343$ \\
\hline \hline
\end{tabular}

TABLE I. Table of continuous phase plate (CPP) parameters used in the current experiments. Columns are CPP name, the beam cone angle (relative to the target-chamber axis) in which the CPPs were used, and the major and minor radii for the resulting elliptical spot.

phase plates (CPPs), which expanded the focal spots and smoothed the intensity distribution within the spot, were installed in each beam line. The resulting elliptical beam spots are given for each cone of beams in Table I. We also applied $45 \mathrm{GHz}$ of smoothing by spectral dispersion (SSD) bandwidth to the seed pulse from the master oscillator. Additionally, we had differential polarization rotation crystals in the beam paths, which separated orthogonal polarizations in each beam, dispersed them, then overlapped them at the position of best focus, which resulted in an additional $\sqrt{2}$ reduction in the intensity variation across the NIF laser spots. 


\section{Diagnostics}

Multiple facility diagnostics were used to measure the energy balance in plasmas created in the gas targets during these experiments. Emitted x-ray flux, reflected laser energy, and hard x-ray emission created by hot electrons were all measured, along with the incident laser power. In this section, we describe the diagnostics used.

\section{Dante-1 and Dante-2}

The Dante- 1 and Dante- $2^{32}$ are 18 channel filtered diode arrays which are installed at the NIF laser facility. These systems provide spectrally and temporally resolved absolute radiation flux measurements from the gas-pipe targets used in these experiments. The spectral coverage and resolution depend upon the combination of filters, mirrors and x-ray diodes (XRDs) chosen for each channel. Typically the Dantes can record emission from 100 $\mathrm{eV}$ to $10 \mathrm{keV}$ with spectral resolution $(\mathrm{E} / \Delta \mathrm{E})$ of 5 to 10 .

Each Dante has a different view of the target as shown in Figure 5. The Dante- 1 is positioned at $\theta=143^{\circ}$ and $\phi=274^{\circ}$, the Dante- 2 is positioned at $\theta=64^{\circ}$ and $\phi=$ $350^{\circ}$. These locations give Dante- 1 and Dante- 2 a view of the target at $37^{\circ}$ and $64^{\circ}$, respectively, from the target's cylindrical axis. The Dantes are located $8.8 \mathrm{~m}$ from the center of the target chamber.

For these shots Dante- 1 had 18 channels with configurations given in Table II for shot N091104. Dante-2 had only 16 active channels and was limited by the number of available digitizers. Its configuration is similar to that of Dante-1. The other four shots had slightly different configurations but basically the same spectral coverage. The Dantes were configured to record emission from 100 eV through $8 \mathrm{keV}$. Each Dante channel was configured with a different set of filters, mirrors and XRD detectors which optimized their coverage for the gas targets. The central energy of each channel is shown in the table, along with the FWHM of the coverage of the channel. Since the gas targets produced significant Xe L-band emission, channel components were choosen to optimize spectral coverage between $4-8 \mathrm{keV}$. These included the $\mathrm{Ti}, \mathrm{Fe}$ and $\mathrm{Zn}$ filtered channels. $\mathrm{A} \mathrm{CaF}_{2}$ filter set was used in each Dante to record the Ar $\mathrm{K}$ emission around $3 \mathrm{keV}$. Where possible, each Dante was configured with an identical channel. This was not always possible since the configurations needed to be compatible with other concurrent experiments.

The data were recorded on SCD5000's for Dante-1 and FTD10000's for Dante-2. The scopes were operated with either a $25 \mathrm{~ns}$ or a $50 \mathrm{~ns}$ total sweep. With a total record of 1024 points, a data point was recorded every 24.4 or 48.8 ps. The ultimate temporal response of the Dante is $\sim 200$ ps, which is limited by the response of the XRDs and the response of the long cables that connect the XRDs to the data recorders.

The absolute flux measurements are possible since each
Dante channel is absolutely calbrated. Each Dante component (e.g. filters, mirrors and XRDs) was individually calibrated $^{33}$ at the Brookhaven synchrotron facility. For each channel, the response of each component in that channel was then convolved together to produce a response function in $\mathrm{GW} / \mathrm{V}$ as a functon of photon energy from 0 to $20 \mathrm{keV}$. The error on the calibration of each channel varies from $10-20 \%$. The spectra at each time point are determined from the response function, the effective source size and an unfold algorithm applied to the recorded voltages from each channel $^{34}$. The flux at a given time point is the sum over each spectrum. For Dante- 1 and 2 the effective source sizes were $19.65 \mathrm{~mm}^{2}$ and $19.89 \mathrm{~mm}^{2}$, respectively, which is the projected area of the target cylinder wall and end cap as viewed by each Dante.

\section{FABS and NBI}

The full-aperture backscatter station (FABS) on NIF uses streaked spectrometers, fast and slow photodiodes, near-field cameras, and time integrated spectrometers to measure independently the characteristics of both the stimulated Brillouin backscattered (SBS) and stimulated Raman backscattered (SRS) light for each of four incident laser beams ${ }^{35,36}$. The FABS has been designed to measure both SBS and SRS backscattered energies between $5 \mathrm{~J}$ and $5 \mathrm{~kJ}$ (total) to within an uncertainty of $18 \%$ at the highest energies. The SBS spectra are measured within a wavelength range of $348-354 \mathrm{~nm}$ with a resolution of $0.03 \mathrm{~nm}$, while the SRS spectra are measured over a range of 430-760 nm with a $2.5 \mathrm{~nm}$ resolution. Both spectral measurements have a temporal resolution of about 200 ps over a 40 ns time window. Also, a near backscattering imaging (NBI) diagnostic system has been implemented on two quads of NIF beams ${ }^{36,37}$. This diagnostic images a flat Lambertian scattering surface inside the target chamber that is mounted around the four beams of a quad spanning angles corresponding to approximately an f/2.5. This instrument quantitatively measures the backscattered light outside of the focusing cone angle of incident laser beams with an $\approx 3 \mathrm{~mm}$ spatial resolution. To account for changes of the system throughput due to exposure to target debris the system is routinely calibrated in situ at 532 and $355 \mathrm{~nm}$ using a dedicated pulsed laser source.

\section{FFLEX}

Hard x-ray signals $(h \nu>25 \mathrm{keV})$ are measured with the NIF's filter-fluorescer (FFLEX) diagnostic system ${ }^{38}$. The FFLEX channels can be configured to measure $\mathrm{x}-$ rays at various energies with a narrow bandpass. Photons from laser-driven experiments are collimated and allowed to pass through a vacuum window before they pass through a prefilter. After they are filtered the photons 

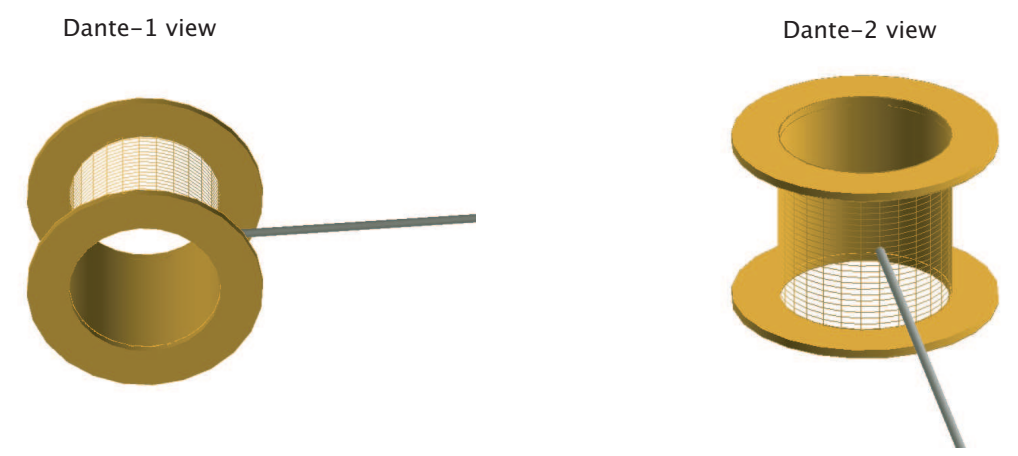

FIG. 5. (color online) (left) Dante- 1 view of gas pipe target at $37^{\circ}$ with respect to the target's (chamber's) axis, (right) Dante-2 view of gas pipe target at $64^{\circ}$ with respect to the target's (chamber's) axis .

\begin{tabular}{|c|c|c|c|c|c|c|c|}
\hline Channel & Filter & Number & $\overline{\mathrm{XRD}}$ & Ta Grid & $\overline{\text { Mirror }}$ & Energy Range (eV) & Solid Angle \\
\hline 1 & $0.75 \mu \mathrm{m} \mathrm{Al}$ & $\mathrm{x} 2$ & $\mathrm{Cr}$ & - & $\mathrm{B}_{4} \mathrm{C} 7^{\circ}$ & $62.5 \pm 5.9$ & $5.98 \mathrm{e}-7$ \\
\hline 2 & $0.2 \mu \mathrm{m} \mathrm{B} / 0.4 \mu \mathrm{m}$ Lexan & $\mathrm{x} 4$ & $\mathrm{Al}$ & - & $\mathrm{aC} 5^{\circ}$ & $166.5 \pm 14.2$ & $5.88 \mathrm{e}-7$ \\
\hline 3 & $2 \mu \mathrm{m}$ Lexan & $\mathrm{x} 2$ & $\mathrm{Al}$ & - & $\mathrm{SiO}_{2} 3.5^{\circ}$ & $249.2 \pm 23.0$ & $5.74 \mathrm{e}-7$ \\
\hline 4 & $1 \mu \mathrm{m} \mathrm{V}$ & $\mathrm{x} 2$ & $\mathrm{Ni}$ & - & $\mathrm{SiO}_{2} 2.5^{\circ}$ & $470.7 \pm 27.4$ & $5.56 \mathrm{e}-7$ \\
\hline 5 & $12 \mu \mathrm{m} \mathrm{Ni}$ & $\mathrm{x} 2$ & $\mathrm{Cr}$ & - & - & $7331.9 \pm 646.4$ & $6.490 \mathrm{e}-7$ \\
\hline 6 & $0.6 \mu \mathrm{m} \mathrm{Cu}$ & $\mathrm{x} 2$ & $\mathrm{Cr}$ & 0.091 & - & $825.1 \pm 70.8$ & $6.490 \mathrm{e}-7$ \\
\hline 7 & $0.65 \mu \mathrm{m} \mathrm{Zn/0.1 \mu \textrm {CH }}$ & $\mathrm{x} 2$ & $\mathrm{Ni}$ & 0.091 & - & $942.1 \pm 49.2$ & $6.490 \mathrm{e}-7$ \\
\hline 8 & $5.5 \mu \mathrm{m} \mathrm{Mg}$ & $\mathrm{x} 3$ & $\mathrm{Ni}$ & 0.091 & - & $1146.0 \pm 100.9$ & $6.490 \mathrm{e}-7$ \\
\hline 9 & $5 \mu \mathrm{m} \mathrm{Al}$ & $\mathrm{x} 3$ & $\mathrm{Ni}$ & 0.091 & - & $1357.9 \pm 130.9$ & $6.490 \mathrm{e}-7$ \\
\hline 10 & $11 \mu \mathrm{m} \mathrm{Si}$ & $\mathrm{x} 2$ & $\mathrm{Al}$ & - & - & $1711.1 \pm 78.2$ & $6.490 \mathrm{e}-7$ \\
\hline 11 & $7 \mu \mathrm{m} \mathrm{CaF}_{2} / 1 \mu \mathrm{m}$ parylene & $\mathrm{x} 3$ & $\mathrm{Al}$ & - & - & $3136.1 \pm 313.6$ & $6.490 \mathrm{e}-7$ \\
\hline 12 & $25 \mu \mathrm{m}$ Saran & $\mathrm{x} 3$ & $\mathrm{Al}$ & - & - & $2550.8 \pm 181.0$ & $6.490 \mathrm{e}-7$ \\
\hline 13 & $2.5 \mu \mathrm{m} \mathrm{Ag}$ & $\mathrm{x} 2$ & $\mathrm{Al}$ & - & - & $3003.8 \pm 230.8$ & $6.490 \mathrm{e}-7$ \\
\hline 14 & $11 \mu \mathrm{m} \mathrm{Ti}$ & $\mathrm{x} 2$ & $\mathrm{Al}$ & - & - & $4107.5 \pm 410.8$ & $6.490 \mathrm{e}-7$ \\
\hline 15 & $15 \mu \mathrm{m} \mathrm{Fe}$ & $\mathrm{x} 2$ & $\mathrm{Ni}$ & - & - & $6171.6 \pm 616.3$ & $6.490 \mathrm{e}-7$ \\
\hline 16 & $25 \mu \mathrm{m} \mathrm{Zn}$ & $\mathrm{x} 1$ & $\mathrm{Ni}$ & - & - & $8995.2 \pm 380.3$ & $6.490 \mathrm{e}-7$ \\
\hline 17 & $250 \mu \mathrm{m} \mathrm{Al}$ & $\mathrm{x} 1$ & $\mathrm{Ni}$ & - & - & $14451.9 \pm 1445.2$ & $6.490 \mathrm{e}-7$ \\
\hline 18 & $1.0 \mu \mathrm{m} \mathrm{Fe} / 0.65 \mu \mathrm{m} \mathrm{Cr} / 5 \mu \mathrm{m}$ parylene & $\mathrm{x} 1$ & $\mathrm{Ni}$ & 0.091 & - & $3647.2 \pm 364.7$ & $1.773 \mathrm{e}-6$ \\
\hline
\end{tabular}

TABLE II. Configurations of Dante-1 for shot N091104. Columns are: the channel number, the filter(s) present in the channel, the number of each type of filter present, the type of XRD used, the transmission of a Ta wire grid if present, a soft-x-ray mirror (with angle of grazing incidence) if present, the energy range over which that channel had sensitivity, and the solid angle subtended by that channel.

cause the fluorescer foil to fluoresce. The fluorescence photons are then filtered before they are converted to visible light in a scintillator 9at the input of the photomultiplier tube (PMT)) and detected by the PMT. The PMT output is amplified by the preamplifier and displayed on an oscilloscope. In the current configuration the low energy $x$ rays are limited by the NIF vacuum window thickness requirements, therefore there is no need to operate the system under vacuum.

\section{GXD}

The volumetric emission was imaged during the heating of the target by the NIF laser on shots N091012 and N091104. A simple pinhole camera geometry was used to record 16 x-ray images of the target from a side-on view $90^{\circ}$ from the target cylindrical axis. The pinhole camera snout was mounted to one of NIF's Gated x-ray Detectors (GXD) ${ }^{39}$ in one of the equatorial diagnostic instrument manipulators (DIM 90-315). The GXD is a four strip micro-channel plate (MCP) x-ray detector which is coupled to a CCD camera. Each strip can be independently timed so the temporal evolution of a target can be obtained. The width of the gating pulse in the $\mathrm{x}$ ray 
was $\sim 100$ ps and sets the time duration of each recorded image. The timing of each GXD strip was $0.86,1.78,2.73$ and $3.30 \mathrm{~ns}$ after $t_{0}$ for shot N091012 and 0.80, 1.87, 2.98 and $4.08 \mathrm{~ns}$ for shot N091104. This timing was referenced from the center of the MCP. The transit time across the plate of the electrical pulse was $\sim 250$ ps. The errors on the strip timing are \pm 4 ps for strip $1, \pm 4$ ps for strip 2, $\pm 36 \mathrm{ps}$ for strip 3 and \pm 24 ps for strip 4 . The spatial resolution of the $\mathrm{MCP} / \mathrm{CCD}$ system is about $75 \mu \mathrm{m}$ and defines the resolution of the recorded images.

The image snout had a magnification of $1 \times$. The distance from the source to the pinholes was $640 \mathrm{~mm}$ and was equal to the distance from the pinholes to the MCP. The 16 pinholes were $25 \mu \mathrm{m}$ in diameter and mounted in a square configuration. Each pinhole produced a single image on the MCP. Four images were recorded on each of the MCP strips. Two of the GXD images on each strip were filtered with $35 \mu \mathrm{m}$ of $\mathrm{Ti}$ which recorded the image in the 4-5 keV spectal band. The other two images on each strip were filtered with $25 \mu \mathrm{m}$ of $\mathrm{Fe}$, so these images were taken in $\mathrm{x}$ rays with energies of $6-7.1 \mathrm{keV}$. The gain of the MCP varies across the surface by about a factor of 2. The different filerting not only allowed imaging of the target in different spectral bands but also adjusted the flux on the MCP to be roughly the same for each image. For shot N091012, it was discovered that the filters had been reveresed for this shot due to a manufacturing error. Therefore, there was roughly a factor-of-four difference in intensities between the two sets of images. The data were still very good. The filter problem was corrected for shot N091104, which produced excellent images.

\section{RESULTS}

\section{A. X-Ray Flux and Fluence}

Table III summarizes the measured energy in three spectral ranges from the five targets shot in this campaign. The emitted yield is reported for all x-ray energies, $\mathrm{x}$ rays with energies $>1.5 \mathrm{keV}$ and with energies $>3 \mathrm{keV}$. The yields reported here (in units of energy per unit solid angle) are measured with the Dante-1 detector, which has a view of the target at $37^{\circ}$ with respect to the target's axis and thus it sees both emission from the target's LEH and emission through the target's wall (see Fig. 5). The Dante-derived yields are accurate to $\pm 10 \%$ at all energies. As was mentioned above, the first shot (N091012) had only outer-cone laser beams and a different pointing and lower average power per beam than the other four shots. This laser configuration results in the lower yield from this target in the $>1.5$ and $>3 \mathrm{keV}$ ranges relative to the emission over all energies. The other four shots had the outer-cone beams pointed farther into the target, which results in an enhancement of the multi-keV radiation relative to the sub-1.5 keV emission. The trend of higher multi-keV yield with moving the foci of the outer-cone beams is confirmed in the simulations for the target output. The table shows the average emission yields for the three nominally identical shots with a full compliment of 112 beams and $\approx 350 \mathrm{~kJ}$ of drive energy. The last line of the table presents the results from a LASNEX ${ }^{31,40}$ post-shot simulation that uses the as-shot beam configuration and pointing and the best available non-LTE atomic model for the emission from the plasma ${ }^{41}$. For both the $128+4$ and 112 -beam configurations, the modeled emission ${ }^{31}$ is within $5 \%$ of the measurements over all energies, a measurement that is dominated by the sub-1.5 keV emission from M-shell Xe ions. The simulations are $\approx 2-13 \%$ above the measurements for all emission above $1.5 \mathrm{keV}$, and $\approx 20-30 \%$ below the measurements for $\mathrm{x}$-ray energies $>3 \mathrm{keV}$, a range that is dominated by the Xe L-shell emission.

Figure 6 shows the spectra that were unfolded from the Dante-1 measurements for the five shots in this campaign. The features in the Dante spectra are determined by the Dante channel responses (see $\S$ II D 1), not the actual emission spectrum. The spectra are quite similar in overall shape, reflecting the reproducibility of the laser energy delivered to each target. For the case of N091012, which had a different laser configuration than the other shots, one can see that the emission in the $4-6 \mathrm{keV}$ range from Xe L-shell ions is below that for the other shots, while the sub-1 keV emission is slightly above the other curves, reflecting the trend seen in Table III. The suppressed emission in the Xe L-shell region means that the mean ionization state of the Xe ions in the target plasma was less than for the other four shots. Similarly, the Ar $\mathrm{K}$-shell emission at $\approx 3 \mathrm{keV}$ for shot N091012 is slightly enhanced compared to the other four shots, which means that the plasma electron temperature was lower in this one shot, which resulted in a more favorable ionization of the Ar ions and a less favorable ionization of the Xe ions. For the other shots, the plasma temperature was higher and the Ar K-shell ions were (likely) nearly fully stripped.

As was discussed in Section II B, specific requirements on the emitted x-ray power from the target led to the design of the laser pulse shape we employed. Figure 7 shows the measured $x$-ray flux in the three spectral ranges listed in Table III as well as the laser power driving the target. The relative accuracy in the timing of the laserpower diagnostics and the Dante diagnostics is better than 200 ps. One can see that the power emitted over all x-ray energies tracks the rise of the laser power quite closely, and remains high for several nanoseconds after the laser pulse ends. The $>3 \mathrm{keV}$ emission, on the other hand, ramps moderately to its peak value of $\approx 0.9 \mathrm{TW} / \mathrm{sr}$ at $4 \mathrm{~ns}$, and declines more rapidly than the all-energies waveform after the laser pulse ends. The FWHM for the $>3 \mathrm{keV}$ x-ray power is $\approx 3 \mathrm{~ns}$. The emitted $\mathrm{x}$-ray power for shot N091104 is measurably below that of the 112beam shots that had the full $350 \mathrm{~kJ}$ of drive, consistent with the $7 \%$ lower drive energy in this shot. 


\begin{tabular}{|c|c|c|c|c|c|c|c|c|}
\hline \multirow[b]{2}{*}{ Shot number } & \multirow[b]{2}{*}{$\begin{array}{c}\text { Laser Energy } \\
(\mathrm{kJ})\end{array}$} & \multirow[b]{2}{*}{ beams } & \multicolumn{2}{|c|}{ All energies } & \multicolumn{2}{|c|}{$>1.5 \mathrm{keV}$} & \multicolumn{2}{|c|}{$>3.0 \mathrm{keV}$} \\
\hline & & & $\begin{array}{c}\text { Yield } \\
(\mathrm{kJ} / \mathrm{sr})\end{array}$ & $\begin{array}{c}\mathrm{CE} \\
(\% / \mathrm{sr})\end{array}$ & $\begin{array}{c}\text { Yield } \\
(\mathrm{kJ} / \mathrm{sr})\end{array}$ & $\begin{array}{c}\mathrm{CE} \\
(\% / \mathrm{sr})\end{array}$ & $\begin{array}{c}\text { Yield } \\
(\mathrm{kJ} / \mathrm{sr})\end{array}$ & $\begin{array}{c}\mathrm{CE} \\
(\% / \mathrm{sr})\end{array}$ \\
\hline N091012-003-999 & 352.1 & 132 & 20.62 & 5.9 & 3.61 & 1.0 & 2.44 & 0.7 \\
\hline LASNEX & 350 & 132 & 20.3 & 5.8 & 4.1 & 1.2 & 1.9 & 0.5 \\
\hline N091103-001-999 & 350.1 & 112 & 19.16 & 5.5 & 4.87 & 1.4 & 3.56 & 1.0 \\
\hline N091104-002-999 & 329.4 & 108 & 19.85 & 6.0 & 4.38 & 1.3 & 3.18 & 1.0 \\
\hline N091110-001-999 & 353.0 & 112 & 20.36 & 5.8 & 4.81 & 1.4 & 3.69 & 1.0 \\
\hline N091111-001-999 & 352.2 & 112 & 21.00 & 6.0 & 4.63 & 1.3 & 3.66 & 1.0 \\
\hline Average & 351.8 & & 20.18 & 5.7 & 4.77 & 1.4 & 3.64 & 1.0 \\
\hline LASNEX & 350 & 112 & 21.2 & 6.1 & 4.9 & 1.4 & 2.4 & 0.7 \\
\hline
\end{tabular}

TABLE III. X-ray yields and CE's per steradian as measured with the Dante-1 detector. Columns are the shot number, the measured laser energy on target, and then the measured yields and laser-to-x-ray CE across all emitted energies, for $\mathrm{x}$ rays with energies $>1.5 \mathrm{keV}$ and with energies $>3 \mathrm{keV}$. Measured x-ray yields are accurate to $\pm 10 \%$. Note, average values are only for shots N091012, N091110, N091111. The specific outputs from post-shot simulations of the Dante-1 view of the target are listed for each of the two laser configurations.

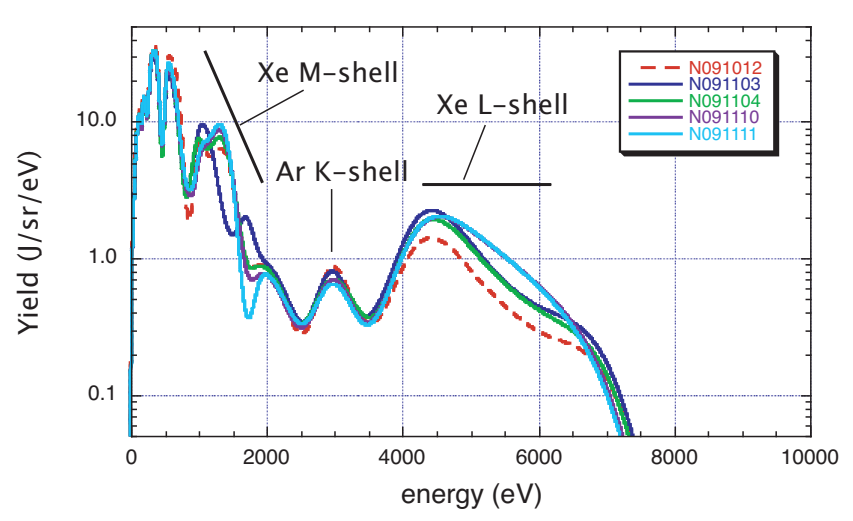

FIG. 6. (color) A compilation of x-ray spectra unfolded from the measured Dante-1 signals. The spectral envelope is remarkably reproducible, with small deviations due principally to missing Dante channels. The spectrum for shot N091012 is below the others in the $>3 \mathrm{keV}$ spectral range due to the different pointing and lower per-beam energy of the outer cone beams for that shot.

\section{B. Laser Backscatter}

Table IV summarizes the energy reflected from one inner cone and one outer-cone quad of beams during these experiments. Laser light scattered by electronplasma waves, stimulated Raman scattering (SRS), and by ion-acoustic waves in the plasma, stimulated Brillouin scattering (SBS), are measured with the FABS and NBI systems (see Sec. II D 2). The measured levels of backscatter were small and within acceptable limits for the these experiments. The backscatter gain exponent is proportional to the laser intensity, and is a function of local plasma parameters such as electron temperature and density ${ }^{42}$. The reflected energy is consistently larger on the outer-cone beams (Q36B) than on the inner-cone

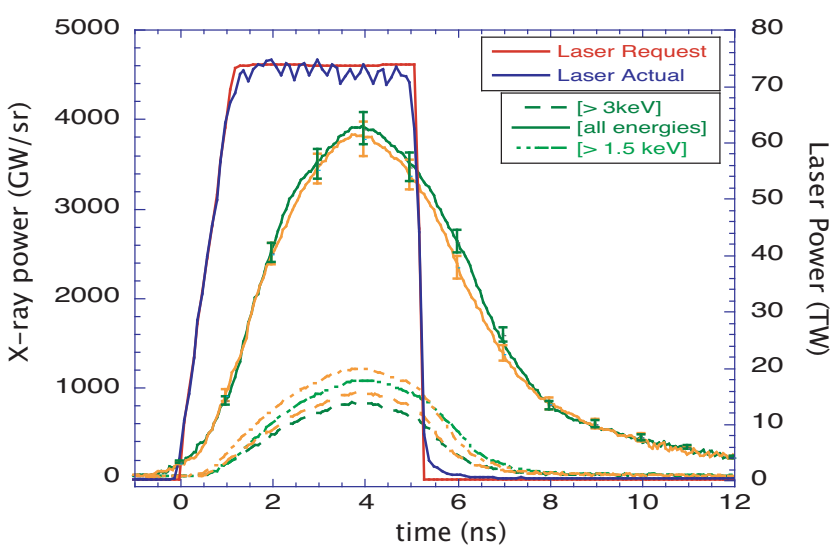

FIG. 7. (color) Measured x-ray power (left scale) for shots N091103 (orange) and N091104 (green) for all emitted photon energies (solid), x-rays with energies $>1.5 \mathrm{keV}$ (dash-dot), and for energies $>3 \mathrm{keV}$ (dashed) and the requested and measured laser power (right scale) for shot N091103. The error bars on the measured $x$-ray flux represent the $\pm 10 \%$ accuracy of the Dante-1 detector.

beams (Q31B). The phase plates used on the outer cone (Rev 1 outer CPPs) produce a smaller laser spot than on the inner cone (Rev 1 inner), leading to an increased laser intensity and hence, increased backscatter. The total fraction of scattered energy measured for both quads in shot N091012 is larger than for the other four shots. The pointing of the outer cone beams for shot N091012 was at the gas pipe's LEH (see $\S$ II C 1), which results in a higher laser intensity and the greater outer-cone SRS in this one shot. For all shots, most of the scattered energy measured for the outer-cone beams is coming from SRS.

The majority of the SRS-scattered light falls outside the entrance apertures of the beams in Q31B and Q36B and onto the calibrated NBI plate, due to refraction of 


\begin{tabular}{|c|c|c|c|c|c|c|c|c|c|c|}
\hline \multirow[b]{2}{*}{ Shot number } & \multicolumn{5}{|c|}{$\overline{\text { Inner Quad 31B }}$} & \multicolumn{5}{|c|}{ Outer Quad 36B } \\
\hline & $\begin{array}{c}\text { energy } \\
(\mathrm{kJ})\end{array}$ & $\begin{array}{c}\text { Intensity } \\
\left(10^{14} \mathrm{~W} / \mathrm{cm}^{2}\right)\end{array}$ & $\begin{array}{c}\text { SRS } \\
(\mathrm{J})\end{array}$ & $\begin{array}{l}\text { SBS } \\
(\mathrm{J})\end{array}$ & $\begin{array}{c}f_{\text {scattered }} \\
(\%)\end{array}$ & $\begin{array}{c}\text { energy } \\
(\mathrm{kJ})\end{array}$ & $\begin{array}{c}\text { Intensity } \\
\left(10^{14} \mathrm{~W} / \mathrm{cm}^{2}\right)\end{array}$ & $\begin{array}{l}\text { SRS } \\
(\mathrm{J})\end{array}$ & $\begin{array}{l}\text { SBS } \\
(J)\end{array}$ & $\begin{array}{c}f_{\text {scattered }} \\
(\%)\end{array}$ \\
\hline N091012-003-999 & 10.69 & 1.17 & 100 & 6 & 1.0 & 11.99 & 2.32 & 417 & 18 & 3.6 \\
\hline N091103-001-999 & 13.97 & 1.52 & 3 & 27 & 0.2 & 13.94 & 2.70 & 93 & 32 & 0.9 \\
\hline N091104-002-999 & 13.68 & 1.49 & 20 & 26 & 0.3 & - & - & - & - & - \\
\hline N091110-001-999 & 13.97 & 1.52 & 23 & 30 & 0.4 & 13.93 & 2.69 & 123 & 27 & 1.1 \\
\hline N091111-001-999 & 13.83 & 1.51 & 17 & 29 & 0.3 & 14.44 & 2.79 & 107 & 28 & 0.9 \\
\hline
\end{tabular}

TABLE IV. Measured backscattered laser energy for the five shots in this campaign. The columns are shot number, quad energy for Q31B, the overlap quad intensity at the position of best focus, the measured energy scattered by the SRS and SBS channels, and the percentage of energy backscattered in both channels relative to the incident laser energy. The same quantities are then listed for Q36B.

the SRS light inside the target. Figure 8 shows the pattern of the scattered SRS light for three shots that had the two different outer-cone laser pointings. The images for the SBS channel are very weak, reflecting the lower level of reflected energy, and the spatial distribution is more concentrated around the beam ports than for the SRS light; the SBS scattered light has nearly the same wavelength as the incident laser light and therefore undergoes similar refraction in the target, back-tracking the path of the laser beams.

The spectral shifts and power histories for scattered SRS light for three shots with both the 128+4- and 112beam configurations are shown in Fig. 9. For the two 112-beam shots the SRS light is red shifted by $\approx 290 \mathrm{~nm}$ to $640 \mathrm{~nm}$ from the wavelength of the incident laser light; for shot N091012, the shift is slightly less, $\approx 280 \mathrm{~nm}$. Note also the presence of a smaller feature in the SRS spectra near $527 \mathrm{~nm}$ that is residual $2 \omega$ light that is present in the target chamber. The power of the scattered laser light is not uniform in time, and is seen to peak $\approx 3.5 \mathrm{~ns}$ into the laser pulse. Both the spectral peak in, and the power histories of the scattered light correlate closely with a laser-plasma interaction calculation (see Appendix A of Strozzi et al. ${ }^{43}$ ) that post-processed the as-shot radiation-hydrodynamic simulations; predicted gain coefficients are presented in Fig. 10. Detailed analysis of the post-processed simulations shows that the dominant outer-cone SRS backscatter largely comes from the beams intercepting blow-off plasma from the lip of the target cylinder that intersects the beam path late in the laser pulse. The simulated peak SRS gain exponent for the outer-cone beams comes at $\approx 3.5-4.0 \mathrm{~ns}$, and at a red-shifted wavelength of $\approx 640 \mathrm{~nm}$, as seen in Fig. 10, in good agreement with the data shown in Fig. 9. The simulated wavelength spread of the back-scattered light, $\approx 620-700 \mathrm{~nm}$, is also in reasonably good agreement with the data. Note finally that the peak SRS gain coefficients are predicted to emerge at earlier times for the 128+4-beam configuration than for the 112-beam configuration, which is consistent with the earlier rise in the data for N091012 in Fig. 9.

\begin{tabular}{lccc}
\hline \hline Shot number & $\begin{array}{c}\mathrm{T}_{1}^{\text {hot }} \\
(\mathrm{keV})\end{array}$ & $\begin{array}{c}\mathrm{T}_{2}^{\text {hot }} \\
(\mathrm{keV})\end{array}$ & $\begin{array}{c}\text { energy >30 keV } \\
(\mathrm{kJ} / \mathrm{sr})\end{array}$ \\
\hline N091012-003-999 & 15.5 & 39.2 & $3.96(-4)$ \\
N091103-001-999 & 12.8 & 35.3 & $9.55(-4)$ \\
N091104-002-999 & 13.5 & 36.4 & $7.88(-4)$ \\
N091110-001-999 & 13.4 & 38.7 & $9.28(-4)$ \\
N091111-001-999 & 13.4 & 38.1 & $9.26(-4)$ \\
\hline \hline
\end{tabular}

TABLE V. Table of FFLEX-determined yields for hot x-ray energy over the spectral range $30-300 \mathrm{keV}$. Columns are shot number, the two temperatures that result from a fit to the measured data for each shot, and the integrated spectral yield between $30-300 \mathrm{keV}$.

\section{High-Energy X-Ray Yield}

Figure 11 shows the measured signals on the multiple channels of the FFLEX detector described in Sec. II D 3 for two shots with the two different laser configurations. The hard-x-ray (i.e., $h \nu>25 \mathrm{keV}$ ) data measured by the FFLEX detector can be described by a two-temperature fit to the set of channels recorded; the fits for the two shots shown in Fig. 11 are shown as solid lines. The two temperatures that come out from the fits, and the total $\mathrm{x}$-ray energy found by integrating the two-temperature spectral reconstruction are listed in Table $\mathrm{V}$ for all five shots in this campaign. While the total amount of energy in the hard-x-ray part of the spectrum is small compared to the energy measured with Dante, it is reported here for completeness. The mechanism for the hard x-ray production is (most likely) the slowing of high-energy "hot" electrons on the positively charged Xe and Ar ions in the target plasma. The hot electrons are likely produced by the resonant scattering of the laser light from plasma electron waves. For the type of target described here, high-energy x-ray backgrounds are likely not a problem for experiments that hope to apply these sources to diagnostic applications. 
N091012-003-999

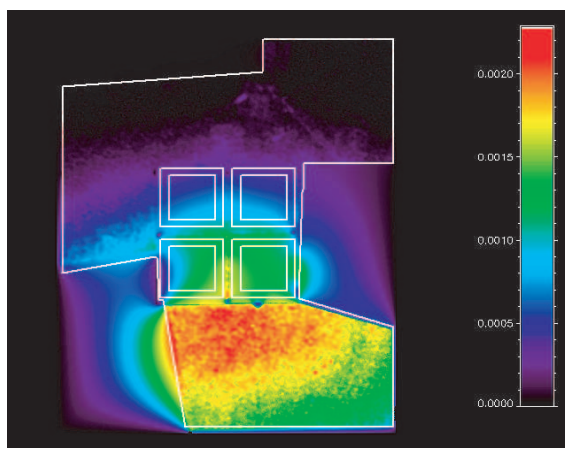

N091103-001-999

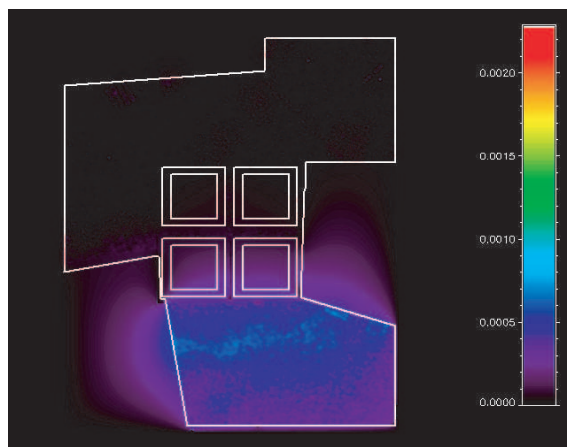

N091110-001-999

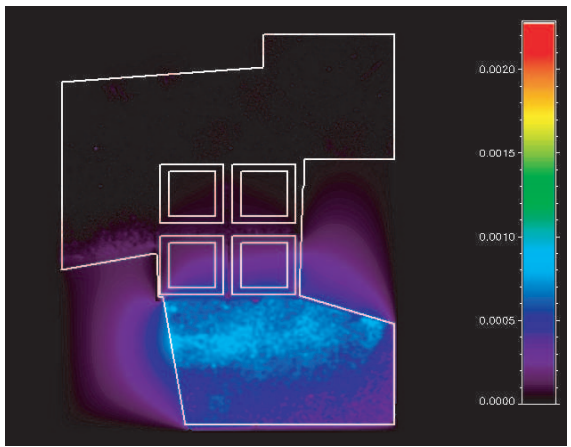

FIG. 8. (color) NBI images of the SRS backscattered light taken around the beam ports for Q36B for three shots with two different beam-pointing configurations. The image on the left is for a shot with the $128+4$-beam configuration, while the other two had the 112-beam configuration. The energy in the beam quad is higher for the two images from the 112-beam-configuration shots while the level of backscattered light is lower.
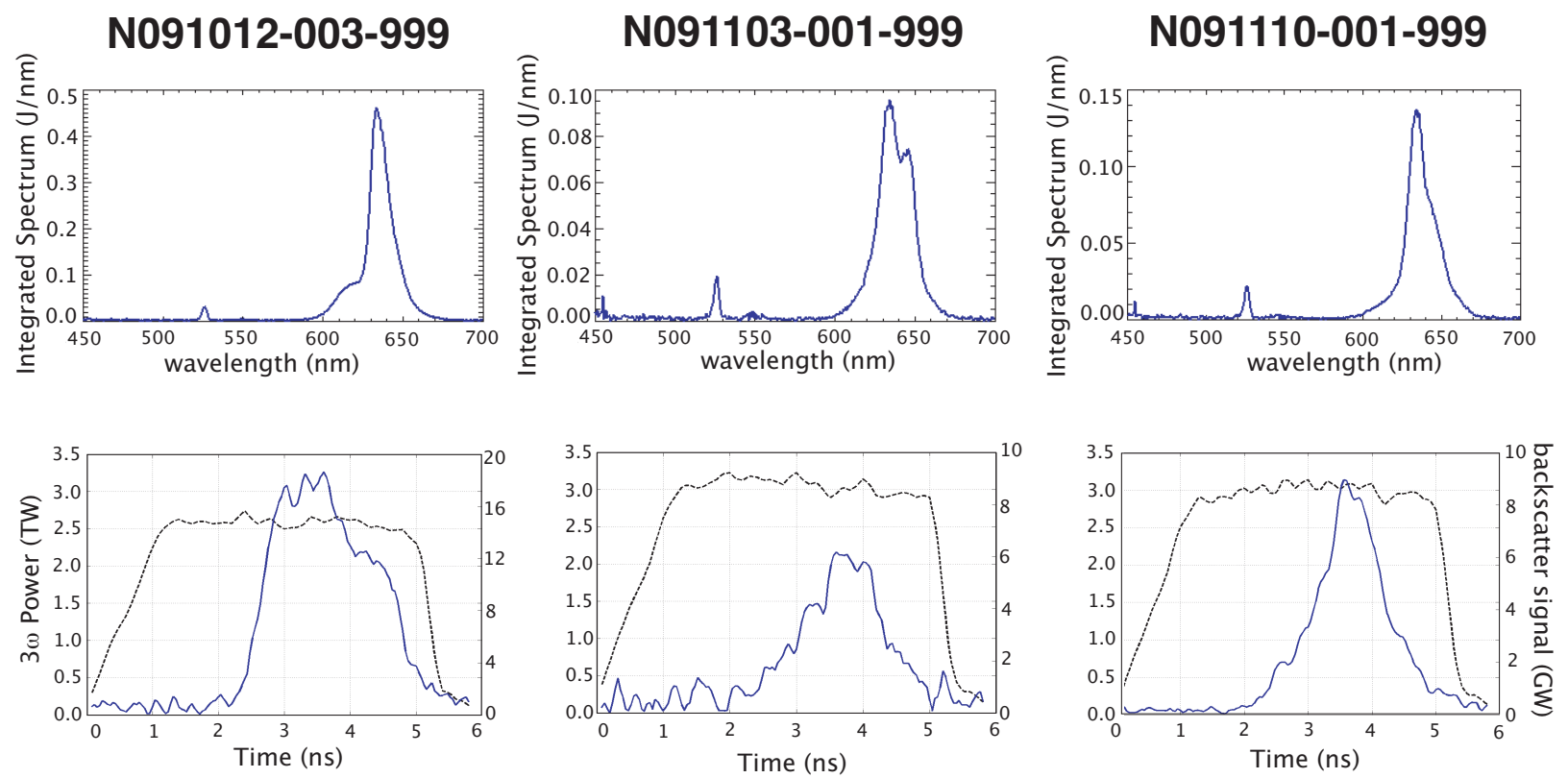

FIG. 9. (color online) (top) SRS scattered-laser-light spectra for an outer-cone quad of beams for three shots with the two different beam configurations and (bottom) power history for SRS reflected light (blue curve, right scales) and the laser power (black curve, left scales) for Q36B. The scattered signal peaks before the end of the laser pulse.

\section{Volume Heating}

Using the GXD, we recorded 16 images of our xray source target during the laser pulse on two shots, N091012, which had the 128+4-beam laser configuration, and N091104, which had 104 beams (the 112 beam laser configuration with eight beams dropped; the diagnostic failed to acquire data on the 112-beam shot N091103). A set of images from each of those shots is shown in Fig. 12. These GXD images were filtered with $35 \mu \mathrm{m}$ of $\mathrm{Ti}$, so the images are taken with $\mathrm{x}$-rays with energies $\gtrsim 3.5 \mathrm{keV}$. The upper set of images is from shot N091104, which has the greater asymmetry in laser intensity when the beams reach the wall of the target cylinder, and which had inner-cone beams, while shot N091012 did not. In both sets of images, one can see emission in the earliest frame from the gas in the small volume made by the polyimide window over the LEH. In the earliest image for shot N091104, at $\mathrm{t}=0.8 \mathrm{~ns}$, one can also see the path of the inner cone beams propagating in the gas, while in the earliest image for shot N091012, which only had outer-cone beams, the larger angle with respect to the target's axis is apparent. As is shown in Fig. 4, the interaction of the unabsorbed laser energy with the target wall is spread over a broad, uniform band for the 128+4beam configuration, and is more concentrated for the 112 

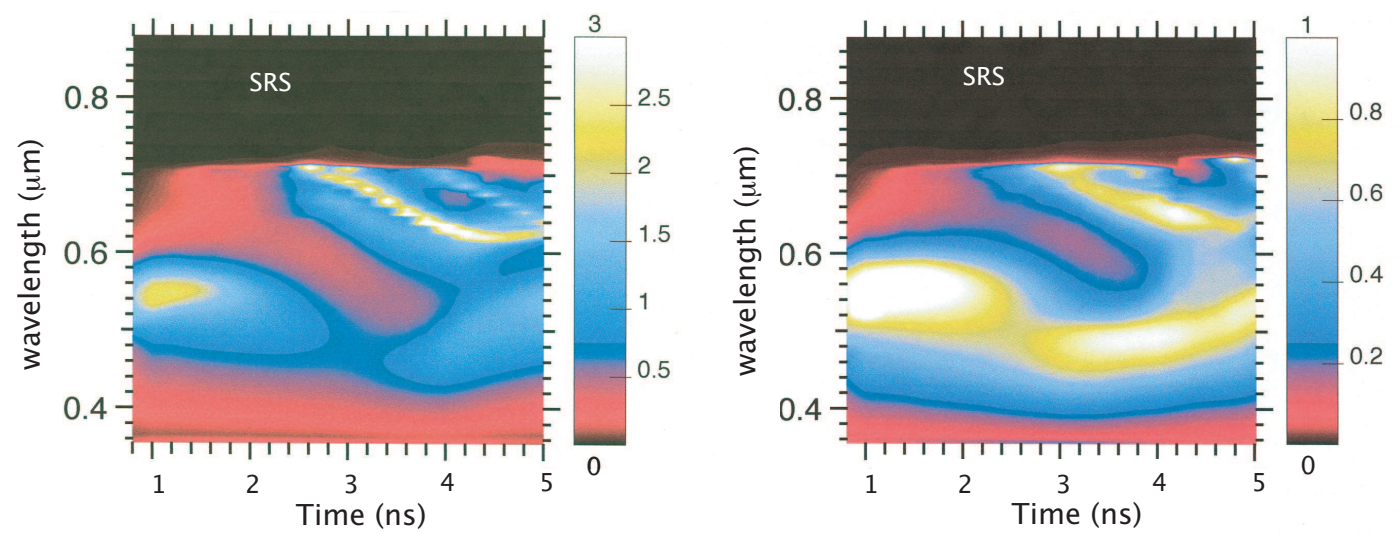

FIG. 10. (color) Scattering figure generated from post-processing ${ }^{43}$ the post-shot $350 \mathrm{~kJ}$ simulations for each beam-pointing configuration. Shown for an outer-cone $\left(50^{\circ}\right)$ quad are the predicted gain coefficients for SRS for (left) the $128+4$ and (right) 112 beam pointing.

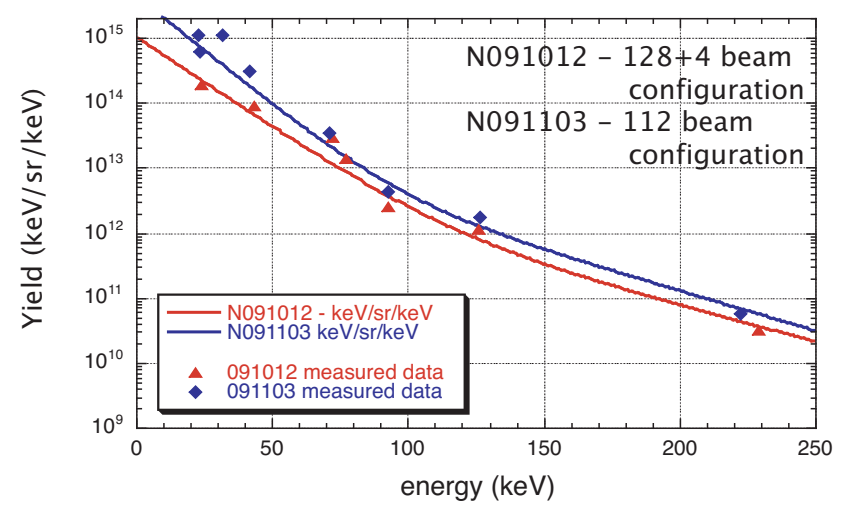

FIG. 11. (color online) FFLEX-measured hard-x-ray yields and the resulting two-temperature fits (excluding the highest energy channel, which has an uncertain calibration).

beam configuration. In the case of shot N091104 (with only 104-beams) there is a pronounced azimuthal asymmetry in the laser deposition due to the missing bundle of beams. Both the more uniform equatorial irradiation for the 128+4-beam configuration and the asymmetry from the dropped beams are apparent in the images in Fig. 12, particularly the second images $(\mathrm{t}=1.68$ and $\mathrm{t}=1.87 \mathrm{~ns}$ for shots N091012 and N091104, respectively). As time goes on in the shots, one also sees that the gas-pipe wall material blows inward causing a compression of the x-ray emitting plasma. In the case of shot N091012, the compression is highly symmetrical from both sides of the pipe in the image. In the case of shot N091104, there is a stronger compression towards the target's axis from the right side of the image that is apparent after $\mathrm{t}=2.98 \mathrm{~ns}$, which is due to the greater intensity in the individual beams heating the target. In the latest-time image for N091012 ( $\mathrm{t}=3.20 \mathrm{~ns})$, there is a dark band in the middle of the target which may be due to either the formation of opposed jets from the target wall that pinch the plasma into two lobes or due to enhanced radiative cooling due to enhanced density on axis from the wall compression.

All the above phenomena are well reproduced in our two-dimensional radiation-hydrodynamic simulations for the targets. Figure 13 shows a simulated GXD x-ray image at $3 \mathrm{~ns}$ for shot N091012 from a post-shot LASNEX simulation and a measured GXD x-ray image from that shot at $3 \mathrm{~ns}$. All the major features of the target evolution are visible in the simulation: the band of uniform laser illumination around the gas pipe's equator, the symmetric compression with two leading lobes above and below the target's mid-plane, and an enhancement of the x-ray emission at the interface between ablated wall material and the heated gas that is due to compressional heating of the plasma at the interface.

\section{DISCUSSION}

\section{A. Supersonic Energy Deposition}

Much work has been done in recent years looking at moderate intensity $\left(I_{\text {las }} \gtrsim 10^{15} \mathrm{~W} / \mathrm{cm}^{2}\right)$ laser propagation in underdense plasmas. In the work in Refs. ${ }^{44-46}$ the targets were all solid at room temperature, unlike the gaseous targets of the present work. The targets were all doped $\mathrm{SiO}_{2}$ aerogels in the few $\mathrm{mg} / \mathrm{cm}^{3}$ density range. $\mathrm{SiO}_{2}$ aerogel is an open-cell foam with pore sizes on the order of $100 \mathrm{~nm}$. To the $351 \mathrm{~nm}$ laser of the present work, there should be little difference in terms of propagating through the ultra-low-density aerogels and a gaseous target. For the present work, from the GXD data we find that the laser has created a multi-keV x-ray emitting 

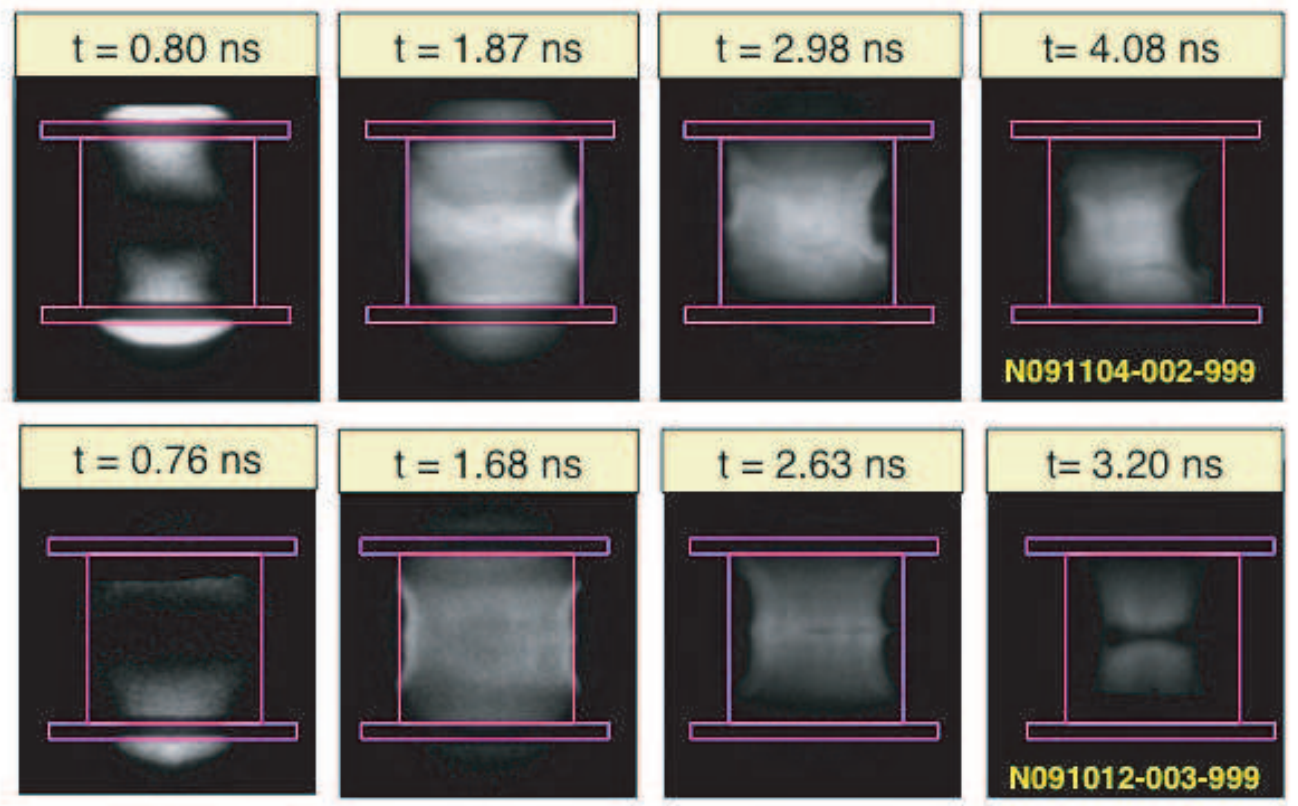

FIG. 12. (color online) GXD images for two shots, taken from a side-on view on the target chamber's equator. The detector was filtered with $35 \mu \mathrm{m}$ of Ti, which transmits only x rays above the Ti K-edge at $\approx 3.5 \mathrm{keV}$. Drawn in magenta is the outline of the gas-pipe target in its position before the shot.

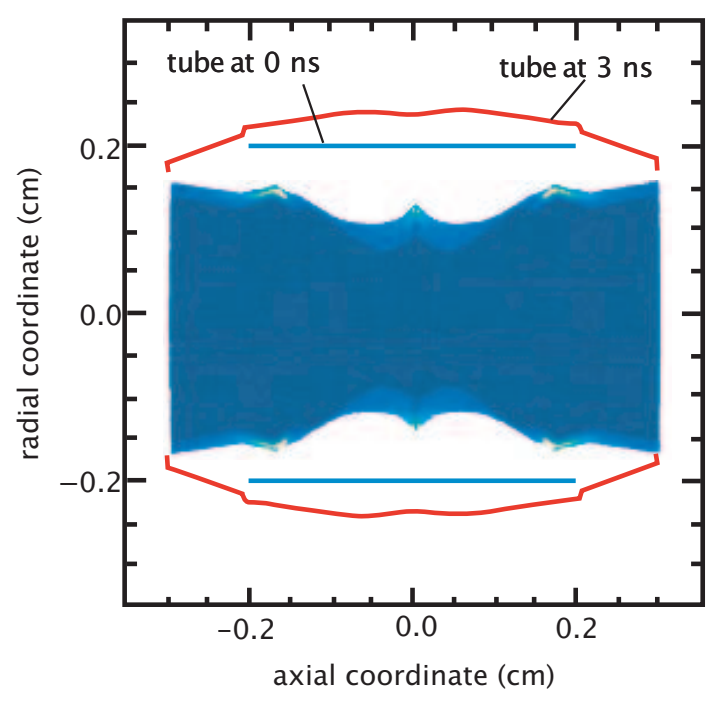

GXD image at $3 \mathrm{~ns}$

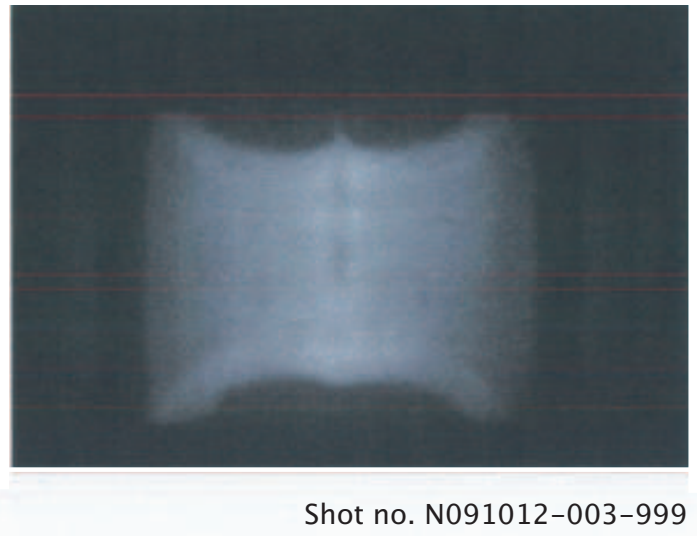

Shot no. N091012-003-999

FIG. 13. (color) (left) Simulated GXD x-ray image at $3 \mathrm{~ns}$ for shot N091012 from a post-shot LASNEX simulation and (right) measured GXD x-ray image at 3 ns. Note, the original position of the epoxy gas pipe and the calculated pipe-plasma boundary at $3 \mathrm{~ns}$ are indicated in the left panel.

plasma in the entire target volume by $\approx 1.5$ ns into the laser pulse. This means, for the $45^{\circ}$ beams, which have a path length through the plasma of $\approx 2.5 \mathrm{~mm}$, and assuming a constant propagation velocity for the laser-energy deposition region, then the laser-energy-deposition front velocity is $v_{\text {dep }} \gtrsim 1.7 \mathrm{~mm} / \mathrm{ns}$. This is $\approx 4$ times greater than the plasma adiabatic sound speed, which for the case that the electrons are hotter than the ions, is given by $c_{s}=\left(\gamma Z k \overline{T_{e}} / M\right)^{1 / 2}=9.79 \times 10^{-3}\left(\gamma Z \overline{T_{e}} / \mu\right)=$ $0.345 \mathrm{~mm} / \mathrm{ns}$, where $\gamma$ is the adiabatic index for the gas, $k$ is Boltzmann's constant, $Z=26.8$ for our Ar-Xe mixture at an average electron temperature $\overline{T_{e}}=2000 \mathrm{eV}$ $\left(Z, \overline{T_{e}}\right.$ both from the LASNEX simulations at $\left.t 1.0 \mathrm{~ns}\right)$, 
and $\mu=71.85$ is the average ionic mass for our gas mixture in units of proton mass. Here, we have used $T_{e}=$ $2 \mathrm{keV}$ for the electron temperature on axis at the time during the laser pulse when the ionization front reaches the gas-pipe wall $(t \leq 1.5 \mathrm{~ns})$. This result is consistent with what was observed previously at similar laser intensities in doped-aerogel targets ${ }^{44}$. We find, as expected, that for these x-ray-source development experiments, which are performed with a laser energy that is more than an order of magnitude larger than what has been done previously ${ }^{15}$, the same enhanced laser-to$\mathrm{x}$-ray conversion efficiency that results from an ionization wave propagating supersonically through the target plasma and heating the entire target's volume.

\section{B. Emitted X-Ray Power}

As discussed in $\S$ III A, we observe that the x-ray power emitted from these targets has different temporal characteristics in different spectral bands. The softest x-ray emission, which comes predominantly from M-shell Xe ions and from radiation reprocessed by the gas-pipe wall material, follows the laser power closely, reflecting the lower ionization energy and faster equilibration time to produce the emitting Xe ions. The lag in the multi-keV $(>3 \mathrm{keV})$ signal is due to the greater energy required to ionize into the L-shell for Xe. We find in our simulations that it is not until after $1 \mathrm{~ns}$ that at least $50 \%$ of the target's volume is at a temperature $>3 \mathrm{keV}$, which is necessary to produce observable Xe L-shell emission. Both the soft x-ray component that dominates the target emission and the multi-keV component peak at $\approx 4 \mathrm{~ns}$ (Fig. 7), which is near the time of the observed maximum compression of the plasma on axis due to the target wall material blowing inwards. It is also near the time of the peak reflected (SRS) laser power (Fig. 9). The xray emission in both M- and L-shell spectral ranges falls rapidly after the laser pulse, which is due to both the lack of a heating source and enhanced radiation losses due to the enhanced plasma electron density that results from the wall compression. Future experiments that will require different $\mathrm{x}$-ray waveforms will have to balance both laser drive sources and the hydrodynamic response of the target volume in crafting the ultimate x-ray power waveform in a specific spectral band.

\section{Laser-to-X-Ray Conversion Efficiency}

Table III reports the laser-to-x-ray conversion efficiency per unit solid angle, as is measured by the Dante detector. If one assumes that the $>3 \mathrm{keV}$ emission is isotropic, which we believe to be the case based on consistency seen between the measurements made with the Dante- 1 and Dante- 2 systems (cf. Fig. 5), then we find a $\mathrm{CE}$ of $13 \pm 1.3 \%$ for emission into $4 \pi$. Previous measurement by Back et al. ${ }^{14}$ on the Nova laser found a $10 \% \mathrm{CE}$ into Xe L-shell emission from a $0.8 \mathrm{~atm}$ (partial pressure) Xe target at $\approx 0.1 n_{c r}$. Further data in Back et al. ${ }^{15}$ found isotropic CE's into Xe L-shell emission ranging from 10$15 \%$ for targets with Xe partial pressures ranging from 1.0 to $2.3 \mathrm{~atm}$. Those experiments used $\approx 18 \mathrm{TW}$ of laser power to drive their x-ray sources. Thus, for a factor of four enhancement in laser power, we see comparable to slightly enhanced laser-to-x-ray CE from our Xe target, which had a Xe partial pressure of only $0.42 \mathrm{~atm}$ and an electron density of $\approx 0.09 n_{c r}$. Applying the trend in CE with increasing target density (i.e., Xe pressure) seen in Fig. 5 of Ref. ${ }^{15}$, we could expect a further $50 \%$ enhancement in $>3 \mathrm{keV}$ laser-to-x-ray $\mathrm{CE}$ for a $1.2 \mathrm{~atm}$ pure $\mathrm{Xe}$ target.

Detailed atomic-kinetics models ${ }^{47}$ explain the enhanced CE in our NIF target (scaled by Xe density) as simply being due to the higher plasma-electron temperatures obtained in the present experiments. Figure 14 shows the calculated radiated power density for a Xe plasma at an electron density of $10^{21} \mathrm{~cm}^{-3}$ for all spectral bands (i.e., integrated over M-, L- and K-shell emission features), and in the L-spectral band as a function of plasma electron temperature. It is clear from the figure that the L-band emission is a strong function of temperature in the range between 1 and $6 \mathrm{keV}$. The strong Mshell contribution to the total radiation is rapidly falling off as the temperature increases, and the L-shell contribution dominates the total radiated power-loss budget for temperatures greater than $\approx 4 \mathrm{keV}$. It is estimated from our LASNEX simulations that for the $\approx 70 \mathrm{TW}$ of laser power used in the present experiments, the volumeaveraged peak plasma-electron temperature in our NIF targets is $\approx 6 \mathrm{keV}$ at $t=4 \mathrm{~ns}$. The vertical lines in the Fig. 14 indicate the maximum plasma-electron temperature likely in a small target driven with $\approx 18 \mathrm{TW}$ of laser power at Omega and the temperature likely achieved in the present NIF experiments. According to the L-band curve in Fig. 14, the temperature difference between the Omega and NIF target plasmas results in an enhancement of $\approx 50 \%$ in the L-band radiative cooling rate. It should be pointed out that the present experiments used only a modest part of NIF's capabilities, about $1 / 5$ of the total energy available, and about $1 / 10$ of the peak laser power available, to drive a target with $1 / 2-1 / 3$ the $\mathrm{Xe}$ density and $\approx 10 \times$ the volume of the targets in Back et $a l .{ }^{14,15}$. If we were to drive a pure Xe target with $200 \mathrm{TW}$ of laser power, and using the scaling from $\mathrm{Lindl}^{48}$ for plasma electron temperature $T_{e} \propto I_{\text {las }}^{2 / 3}$, we can expect a $2 \times$ increase in the volume-averaged plasma electron temperature, which brings us into the saturated regime of the L-shell cooling curve in Fig. 14. Based on these density-scaling and laser-heating-scaling arguments, we estimate a maximum laser-to-L-shell-x-ray CE efficiency for a $1.2 \mathrm{~atm}$ Xe target of $\approx 21 \%$. Future experiments are planned that will heat larger volumes to higher temperatures than was done in the present work and attempt to demonstrate the validity of this estimate. 


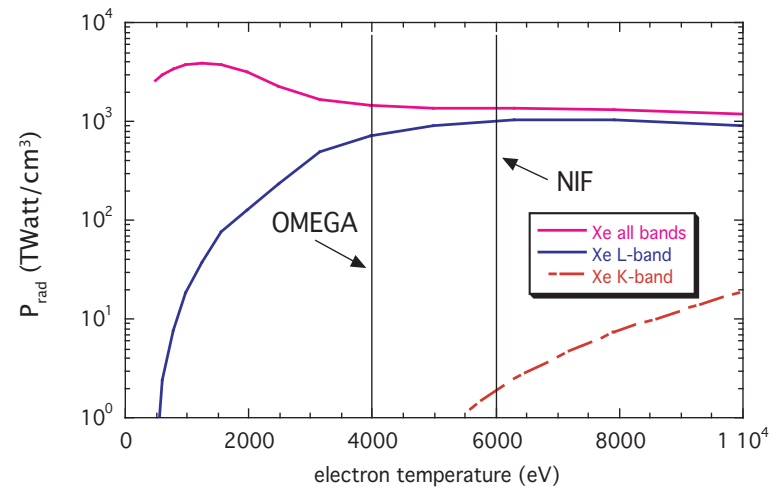

FIG. 14. (color online) Xe radiative-loss cooling curves as a function of plasma electron temperature for emission across all spectral ranges, in the L-band (3-7 keV), and the K-band spectral range $(>29 \mathrm{keV})$. Data provided by private communication from S. B. Hansen at Sandia National Laboratories.

\section{CONCLUSIONS AND FUTURE WORK}

In summary, we have confirmed a prediction of enhanced CE from laser-driven plasma radiation sources that are driven with laser power $>70 \mathrm{TW}$. High-precision data on the plasma x-ray emission, the plasma heating, and the dynamics of the laser target during the experiment were taken. The agreement between the measured and predicted x-ray yields in Table III, the measured and predicted spectral shift of scattered laser light in Sec. III B and the measured and simulated hydrodynamics of our x-ray-source targets in Fig. 13 give us high confidence in our ability to predict the x-ray yield, laser coupling and target heating, and x-ray-power histories for future experiments. However, many open questions remain. In the present experiments, we used $\approx 1 / 5$ of NIF's available energy and delivered $\approx 72 \mathrm{TW}$ of laser power to target. It remains to be seen how efficient we can make this x-ray source with greater laser energy and power. Further, previous calculations ${ }^{26}$ for K-shell $\mathrm{Kr}$ emission at $13 \mathrm{keV}$ have seen an equally striking improvement in the laser-to-x-ray CE for NIF-scale targets at NIF-scale temperatures; nearly all applications for bright x-ray sources benefit from higher photon energies in the source output. It is unknown whether we could get an efficient conversion of NIF laser energy into K-shell Xe x-rays at $30 \mathrm{keV}$ (see Fig. 14, but it is an investigation worth pursuing). For certain applications, such as the study of x-ray driven electromagnetic phenomena, or radiography of high-density objects, high-energy, deeply penetrating x-ray photons are required. In addition to the K-shell $\mathrm{Kr}$ and Xe sources, x-ray sources at other energies need to be developed; for example, pre-exploded metal foils ${ }^{22,23}$, foil-lined cylinders ${ }^{24}$, metal nano-fiber low-density $\operatorname{targets}^{21}$, and metal-doped aero- gel materials ${ }^{20}$ are all candidates for highly efficient $\mathrm{x}$ ray sources. In conclusion, an enormous expanse of x-ray source development activities exist, now that an unexplored regime of laser energy and power is available at the NIF.

\section{ACKNOWLEDGMENTS}

The authors would like to thank the entire NIF operations staff for their tireless and exemplary support of these experiments. Certain individuals, including Glenn Heestand, Chris Haynam, Bill Gourdin, Russell Wallace, Tom Parham, Sandra Brereton, John Celeste and Leon Berzins made crucial contributions without which these shots never would have happened. This work performed under the auspices of the U. S. Department of Energy by Lawrence Livermore National Laboratory under Contract DE-AC52-07NA27344. This work was also supported by the Defense Threat Redution Agency under the IACRO 09-45501 "Evaluation of Lasers for X-Ray Production on NIF".

${ }^{1}$ O. L. Landen, D. R. Farley, S. G. Glendinning, L. M. Logory, P. M. Bell, J. A. Koch, F. D. Lee, D. K. Bradley, D. H. Kalantar, C. A. Back, et al., Rev. Sci. Instru. 72, 627 (2001).

${ }^{2}$ B. E. Blue, J. F. Hansen, and H. F. Robey, Rev. Sci. Instrum. 75, 3989 (2004).

${ }^{3}$ R. Tommasini, H.-S. Park, P. Patel, B. Maddox, S. Le Pape, S. P. Hatchett, B. A. Remington, M. H. Key, N. Izumi, M. Tabak, et al., in Atomic Processes in Plasmas, edited by Gillaspy, JD and Curry, JJ and Wiese, WL, (Amer. Inst. of Physics, 2007), vol. 926 of AIP Conf. Proc., pp. 248-255.

${ }^{4}$ H. S. Park, B. R. Maddox, E. Giraldez, S. P. Hatchett, L. T. Hudson, N. Izumi, M. H. Key, S. Le Pape, A. J. MacKinnon, A. G. MacPhee, et al., Phys. Plasmas 15 (2008).

${ }^{5}$ B. E. Blue, S. V. Weber, S. G. Glendinning, N. E. Lanier, D. T. Woods, M. J. Bono, S. N. Dixit, C. A. Haynam, J. P. Holder, D. H. Kalantar, et al., Phys. Rev. Lett. 94, 095005 (2005).

${ }^{6}$ O. L. Landen et al., Eur. Phys. J. D 44, 273 (2007).

${ }^{7}$ A. B. Reighard, S. G. Glendinning, P. E. Young, W. W. Hsing, M. Foord, M. Schneider, K. Lu, T. Dittrich, R. Wallace, and C. Sorce, Rev. Sci. Instrum. 79, 10E915 (2008).

${ }^{8}$ K. B. Fournier, C. Sorce, M. May, M. Tobin, V. Rekow, D. Beutler, C. Coverdale, R. Gallegos, K. Dudley, D. Osborne, et al., J. Radiat. Eff. 26, 99 (2009).

${ }^{9}$ J. Fisher, C. Newlander, K. Fournier, M. May, M. Tobin, D. Beutler, C. Coverdale, J. Davis, D. Shiekh, J. Radiat. Eff. 26, 59 (2009).

${ }^{10}$ T. Stringer, N. Dumcum, D. Beutler, C. Coverdale, J. Dudley, J. Jones, D. Osborne, K. Fournier, J. Radiat. Eff. 26, 71 (2009).

${ }^{11}$ K. B. Fournier, M. J. May, J. D. Colvin, C. Sorce, J. Emig, V. Rekow, J. H. Fisher, C. D. Newlander, R. Horton, D. Osborne, K. J. Dudley, et al., J. Radiat. Eff. 28, 33 (2010).

${ }^{12}$ J. Workman and G. A. Kyrala, Rev. Sci. Instru. 72, 678 (2001).

${ }^{13} \mathrm{~J}$. Workman and G. A. Kyrala, in Applications of X Rays Generated from Lasers and Other Bright Sources II, edited by G. A. Kyrala and J.-C. J. Gauthier (SPIE, 2001), vol. 4504, pp. 168179.

${ }^{14}$ C. A. Back, J. Grun, C. Decker, L. J. Suter, J. Davis, O. L. Landen, R. Wallace, W. W. Hsing, J. M. Laming, U. Feldman, et al., Phys. Rev. Lett. 87, 275003 (2001).

${ }^{15}$ C. A. Back, J. Davis, J. Grun, L. J. Suter, O. L. Landen, W. W. Hsing, and M. C. Miller, Phys. Plasmas 10, 2047 (2003). 
${ }^{16}$ K. B. Fournier, C. Constantin, J. Poco, M. C. Miller, C. A. Back, L. J. Suter, J. Satcher, J. Davis, and J. Grun, Phys. Rev. Lett. 92, 165005 (2004).

${ }^{17}$ K. Fournier, C. Constantin, G. Gregori, M. Miller, C. Back, L. Suter, J. Davis, and J. Grun, in Atomic Processes in Plasmas, edited by Cohen, JS and Mazevet, S and Kilcrease, DP, (Amer. Inst. of Physics, 2004), vol. 730 of AIP Conf. Proc., pp. 223-232.

${ }^{18}$ K. B. Fournier, M. Tobin, J. F. Poco, K. Bradley, C. A. Coverdale, D. E. Beutler, T. Vidnovic III, S. B. Hansen, M. Severson, E. A. Smith, et al., in Laser-Generated \& Other Lab. Xray $\& 5$ EUV Sources, Optics, Apps., edited by G. A. Kyrala, J.-C. Gauthier, C. A. MacDonald, and A. M. Khounsary (SPIE, 2005), vol. 5918 of Proc. of SPIE, pp. 5918N1-10.

${ }^{19}$ K. B. Fournier, C. Constantin, C. A. Back, L. Suter, H.-K. Chung, M. C. Miller, D. H. Froula, G. Gregori, S. H. Glenzer, and O. L. Landen, J. Quant. Spect. and Rad. Transf. 99, 186 (2006).

${ }^{20}$ K. B. Fournier, J. H. Satcher, M. J. May, J. F. Poco, C. M. Sorce, J. D. Colvin, S. B. Hansen, S. A. MacLaren, S. J. Moon, J. F. Davis, et al., Phys. Plasmas 16, 052703 (2009).

${ }^{21}$ M. Tanabe, H. Nishimura, S. Fujioka, K. Nagai, N. Yamamoto, Z.-Z. Gu, C. Pan, F. Girard, M. Primout, B. Villette, et al., Appl. Phys. Lett. 93 (2008).

${ }^{22}$ F. Girard, J. P. Jadaud, M. Naudy, B. Villette, D. Babonneau, M. Primout, M. C. Miller, R. L. Kauffman, L. J. Suter, J. Grun, et al., Phys. Plasmas 12, 092705 (2005).

${ }^{23}$ D. Babonneau, M. Primout, F. Girard, J. P. Jadaud, M. Naudy, B. Villette, S. Depierreux, C. Blancard, G. Faussurier, K. B. Fournier, et al., Phys. Plasmas 15 (2008).

${ }^{24}$ F. Girard, M. Primout, B. Villette, P. Stemmler, L. Jacquet, D. Babonneau, and K. B. Fournier, Phys. Plasmas 16 (2009).

${ }^{25}$ J. Denavit and D. W. Phillion, Phys. Plasmas 1, 1971 (1994).

${ }^{26}$ H.-K. Chung, K. B. Fournier, and R. W. Lee, High Energy Density Physics 2, 7 (2006).

${ }^{27}$ E. I. Moses, R. E. Bonanno, C. A. Haynam, R. L. Kauffman, B. J. MacGowan, and R. W. Patterson Jr, Eur. Phys. J. D 44, 215 (2007).

${ }^{28}$ C. A. Haynam, P. J. Wegner, J. M. Auerbach, M. W. Bowers, S. N. Dixit, G. V. Erbert, G. M. Heestand, M. A. Henesian, M. R. Hermann, K. S. Jancaitis, et al., Appl. Optics 46, 3276 (2007).

${ }^{29}$ E. M. Campbell, J. T. Hunt, E. S. Bliss, D. R. Speck, and R. P. Drake Rev. Sci. Instrum. 57, 2101 (1986).

${ }^{30}$ T. R. Boehly, D. L. Brown, R. S. Craxton, R. L. Keck, J. P. Knauer, J. H. Kelly, T. J. Kessler, S. A. Kumpan, S. J. Loucks, S. A. Letzring, F. J. Marshall, R. L. McCrory, S. F. B. Morse, W. Seka, J. M. Soures, C.P. Verdon, Opt. Commun. 133, 495-506 (1997).
${ }^{31}$ J. D. Colvin, K. B. Fournier, M. J. May, and H. A. Scott, A Computational Study of X-ray Emission from Laser-Irradiated Ge-doped Foams (2010), submitted to Phys. Plasmas.

${ }^{32}$ E. L. Dewald, K. M. Campbell, R. E. Turner, J. P. Holder, O. L. Landen, S. H. Glenzer, R. L. Kauffman, L. J. Suter, M. Landon, M. Rhodes, et al., Rev. Sci. Instrum. 75, 3759 (2004).

${ }^{33}$ K. M. Campbell, F. A. Weber, E. L. Dewald, S. H. Glenzer, O. L. Landen, R. E. Turner, and P. A. Waide, Rev. Sci. Instrum. 75, 3768 (2004).

${ }^{34}$ A. Seifter and G. A. Kyrala, Rev. Sci. Instrum. 79, 10 F323 (2008).

${ }^{35}$ D. H. Froula, D. Bower, M. Chrisp, S. Grace, J. H. Kamperschroer, T. M. Kelleher, R. K. Kirkwood, B. MacGowan, T. McCarville, N. Sewall, et al., Rev. Sci. Instrum. 75, 4168 (2004).

${ }^{36}$ J. D. Moody, P. Datte, K. Krauter, R. H. E. Bond, P. Michel, B. J. MacGowan, S. H. Glenzer, L. Sutter, N. Meezan, R. London, et al., Bull. of the Am. Physical Society 54 (2009).

${ }^{37}$ A. J. Mackinnon, T. McCarville, K. Piston, C. Niemann, G. Jones, I. Reinbachs, R. Costa, J. Celeste, G. Holtmeier, R. Griffith, et al., Rev. Sci. Instrum. 75, 4183 (2004).

${ }^{38}$ J. W. McDonald, R. L. Kauffman, J. R. Celeste, M. A. Rhodes, F. D. Lee, L. J. Suter, A. P. Lee, J. M. Foster, and G. Slark, Rev. Sci. Instrum. 75, 3753 (2004).

${ }^{39}$ J. A. Oertel, R. Aragonez, T. Archuleta, C. Barnes, L. Casper, V. Fatherley, T. Heinrichs, R. King, D. Landers, F. Lopez, et al., Rev. Sci. Instrum. 77, 10E308 (2006).

${ }^{40}$ G. Zimmerman and W. Kruer, Comments Plasma Phys. Control. Fusion 2, 51 (1975).

${ }^{41}$ H. A. Scott and S. B. Hansen, High Energy Density Physics 6, 39 (2010).

${ }^{42}$ W. L. Kruer, The Physics of Laser Plasma Interactions (Westview Press, 2003).

${ }^{43}$ D. J. Strozzi, E. A. Williams, D. E. Hinkel, D. H. Froula, R. A. London, and D. A. Callahan, Phys. Plasmas 15, 102703 (2008).

${ }^{44}$ C. Constantin, C. A. Back, K. B. Fournier, G. Gregori, O. L. Landen, S. H. Glenzer, E. L. Dewald, and M. C. Miller, Phys. Plasmas 12, 063104 (2005).

${ }^{45}$ M. Tanabe, H. Nishimura, S. Fujioka, K. Nagai, A. Iwamae, N. Ohnishi, K. B. Fournier, F. Girard, M. Primout, B. Villette, et al., Journal of Physics: Conference Series 112, 022076 (2008).

${ }^{46}$ M. Tanabe, H. Nishimura, N. Ohnishi, K. B. Fournier, S. Fujioka, A. Iwamae, S. B. Hansen, K. Nagai, F. Girard, M. Primout, et al., High Energy Density Physics 6, 89 (2010).

${ }^{47}$ S. Hansen, J. Bauche, C. Bauche-Arnoult, and M. Gu, High Energy Density Physics 3, 109 (2007).

${ }^{48} \mathrm{~J}$. D. Lindl, Inertial Confinement Fusion (Springer-Verlag, 1998), see chapter 10. 